\title{
Exploring individual and population eco-evolutionary feedbacks under the coupled effects of fishing and predation
}

\section{Jusufovski, Dunja}

2020-11

Jusufovski , D \& Kuparinen , A 2020 , ' Exploring individual and population eco-evolutionary feedbacks under the coupled effects of fishing and predation ' , Fisheries Research, vol. 231 , 105713 . https://doi.org/10.1016/j.fishres.2020.105713

http://hdl.handle.net/10138/324662

https://doi.org/10.1016/j.fishres.2020.105713

submittedVersion

Downloaded from Helda, University of Helsinki institutional repository.

This is an electronic reprint of the original article.

This reprint may differ from the original in pagination and typographic detail.

Please cite the original version. 
1 Exploring individual and population eco-evolutionary feedbacks under the coupled effects of

fishing and predation

3

4

5 Dunja Jusufovski ${ }^{a^{*}, 1}$ and Anna Kuparinen ${ }^{\mathrm{b}}$

6

7 arganismal and Evolutionary Biology Research Program, University of Helsinki, P.O. Box 65,

$8 \quad 00014$ Helsinki, Finland; dunja.jusufovski@helsinki.fi

$9 \quad{ }^{b}$ Department of Biological and Environmental Sciences, University of Jyväskylä, P.O. Box 35, 40014

10 Jyväskylä, Finland; anna.k.kuparinen@jyu.fi

$11 *$ Corresponding author

12

13

14

15

16

17

18

19

20

21

22

23

Running head: Eco-evolutionary feedbacks under fishing and predation

Abbreviations:

FRII - Holling's functional response Type II

FRIII - Holling's functional response Type III

${ }^{1}$ Corresponding author's present address and mobile phone number: Ulica kneza Domagoja 1, 31220

Višnjevac, Croatia; +385(0)915609853 


\section{Abstract}

Intensive fishing that selects for large and old individuals can have pervasive effects on traits directly associated with the fecundity and survival of the target species. The observed reduction in fish body size can result in earlier sexual maturity at a smaller body size, leading to a lower individual reproductive output and population productivity in the long term. In addition, increased predation can induce similar responses in age and size at maturity due to the release of intraspecific competition and the lower population density. Thus, the combined impact of fisheries and predation is more difficult to predict due to their competition for fish, ultimately limiting and directing the prey size selectivity of each competitor. This can lead to various responses of fish on individual and population levels, depending on how the impacts of fisheries and predation affect each other. To explore this topic, we used an individual-based model to investigate the responses of the European hake (Merluccius merluccius) to the coupled pressures of the prevailing fishing regime and predation by bottlenose dolphins (Tursiops truncatus) as a study system. By simulating the growth trajectories of hake with consideration to its pronounced sexual size dimorphism (SSD), we applied Holling's Type II and III functional responses (FRII and FRIII, respectively) and the Rosenzweig-MacArthur predator model to describe prey-predator dynamics. Our results demonstrate how the intensity, duration, and prey sizes selected by predation and fisheries determine the potential for evolutionary changes in hake life-history traits. Additionally, pronounced SSD in hake as well as the predation type play a pivotal role in hake resilience and recovery following a period of overexploitation. Different types of predation reveal the discrepancy in the intensity of competition between predators and fisheries for fish, as well as predator survival, which is relevant for sustainable fisheries management and effective predator conservation strategies. 


\section{Introduction}

Fisheries-induced alterations in fish morphology, behavior, and development have been a focus of research and discussion in fisheries science and management for the past several decades (e.g., Hendry et al., 2011; Palkovacs et al., 2012; Heino et al., 2015). A number of researchers have emphasized the negative, long-term, and potentially irreversible effects of fisheries-induced evolution (FIE) on fish stock resilience and recovery (Swain et al., 2007; Enberg et al., 2009; Neubauer et al., 2013), as well as sustainable fisheries yields (Zhou et al., 2010; Garcia et al., 2012). In particular, the size selectivity of fisheries and removal of larger and older individuals poses a persistent threat due to its pervasive, damaging effects on individual fecundity and survival (Law, 2000; Palkovacs et al., 2012; Belgrano and Fowler, 2013). Continued high harvest rates and fishing intensity, selecting for life-history traits with specific heritability, represent the main conditions that can induce an evolutionary shift in fish species (Hutchings and Kuparinen, 2019). However, difficulties in distinguishing phenotypic plasticity from evolution (reviewed in Hendry, 2016) and discerning the direction of ecology-to-evolution or evolution-to-ecology processes are the main obstacles to proving FIE in harvested fish stocks (see Hendry et al., 2011; Heino et al., 2015).

In addition to FIE, predation and other selective pressures of environmental and ecological origin occurring in marine ecosystems can potentially induce similar responses in the direction or magnitude of targeted phenotypic traits (see Reznick et al., 1990; Philips et al., 2010; Crozier and Hutchings, 2014; Ohlberger, 2013; Waples and Audzijonyte, 2016). Predation is, among others, a size-selective source of natural mortality, removing individuals according to the prey size selectivity of the predator. Moreover, the size-dependent mortality caused by predation increases with a decrease in fish body size, especially in those predators limited by gape size (Pettorelli et al., 2011). Similarly to fisheries, predation directly affects the prey's investment to reproduction (DeLong and Luhring, 2018) and its reproductive success or resilience (Lowerre-Barbieri et al., 2017) to other disturbances. This can ultimately lead to shifts in the timing of their sexual 
maturation and alter their reproductive strategy (e.g., behavioral patterns linked to reproduction) due to the removal of sexually mature individuals. While such predation-induced changes in prey have been detected as shifts in size and age at maturity observed under experimental conditions (Beckerman et al., 2010), changes in predators induced by the changes in prey have also been observed. For instance, Shuter et al. (2015) predicted that larger size ratios of lake trout (Salvelinus namaycush, predator) to cisco (Coregonus artedii, prey) lead to earlier maturity at a smaller size in the predator species. Thus, prey characteristics as well as their adaptions to predation affect predator development and abundance (Yamamichi and Miner, 2015; Fryxell et al., 2019).

Considering that fishing can erode size-dependent interactions, change community compositions, and weaken the structural integrity of ecosystems (Palkovacs et al., 2012; Bell et al., 2018), evolutionary changes in individual fish traits can reinforce these shifts and limit or reduce intraspecific genotypic diversity, which ultimately diminishes fishing yields (Law and Grey, 1989; Garcia et al., 2012; Belgrano and Fowler, 2013). As a result, concern has been raised regarding the management of evolving fish stocks and their implications for ecosystem functioning and sustainable fisheries yields. Recent managerial advice for fish populations has included the application of balanced harvesting (Law and Plank, 2018), as well as the active monitoring and accountability of individual trait responses to fishing and other selective pressures (Conover and Munch, 2002; Palkovacs et al., 2018). Furthermore, particular attention should be given to exploitation strategies for late and early maturing species (Ernande et al., 2004), as well as to fish stocks already demographically and genetically altered, which require careful implementation of different fishing moratoria (de Roos et al., 2006). However, these proposed measures are accompanied by various operational and logistical difficulties, and they only address fisheriesinduced alterations in individual and population parameters, other threats such as climate change notwithstanding (Fraser, 2013; Palkovacs et al., 2018). 
In harvested ecosystems, fisheries and natural predators often compete for the same target fish in areas of temporal and spatial resource overlap. To account for this, the majority of fish stock assessments include predation as part of a species-specific fixed value for natural mortality that is equally applied across all age and size classes of fish (Gislason et al., 2010). However, the risk of being consumed by a predator decreases as a function of increasing body size, as bigger prey fish become more elusive due to their size (Abrams and Ginzburg, 2000), as well as their improved swimming and maneuvering skills (Scharf et al., 2000; DeLong and Luhring, 2018). From the predator's viewpoint, their prey size selectivity will change and adjust according to prey availability and the predator's ontogenetic development (Griffiths, 1975). While humans are considered as predators, their prey selectivity and preference are not governed by the sole need to feed for survival. As Darimont et al. (2015) concluded, humans are not limited in their exploitation rates or techniques as natural predators are; thus, humans are considered as "super predators". As a consequence of intensive harvesting, humans can alter the predation risk through direct impacts on predators as well as indirectly by affecting the physical environment (see Madin et al., 2016). Further negative impacts can occur through density-mediated effects (Lankau and Strauss, 2011) where the removal of large predators has direct implications for the strength of trophic cascades as well as food web stability (DeLong et al., 2015).

The European hake (Merluccius merluccius, Linnaeus, 1758) is a gadoid bottom-dweller inhabiting the seas along the NE and central E Atlantic, the NW African coast, and the Mediterranean and Black Seas, with a decreasing presence from west to east (Fig. 1; Sion et al., 2019). Adult hake have a mainly piscivorous diet and exhibit strong sexual size dimorphism (SSD), with males maturing earlier and having a shorter lifespan than females (Cerviño, 2014; Murua, 2010). Furthermore, the female body size in hake is not just positively correlated with the number of produced eggs (i.e., individual fecundity), but also with the quality of the produced eggs, which ensures a higher chances of offspring survival (Mehault et al., 2010). Significant fluctuations in size 
at maturity have been observed in hake populations of the Bay of Biscay and Galician waters (Domínguez-Petit et al., 2008). Although these changes have been attributed to phenotypic plasticity of various strengths (see Hidalgo et al., 2014), these populations have experienced very high harvest rates since the 1980s and continue to do so (ICES, 2019). Additionally, hake are preyed upon by the bottlenose dolphin (Tursiops truncatus, Montagu, 1821), which has been confirmed by dietary studies on the Irish, Bay of Biscay, and Galician, as well as the W Mediterranean bottlenose dolphin populations (Blanco et al., 2001; Fernández et al., 2011; Hernandez-Milian et al., 2015; Santos et al., 2007, 2014). These opportunistic predators often interact with fishing activities (i.e., operational interactions; Bearzi et al., 2008), following trawlers or depredating on coastal nets (e.g., López, 2006; Bearzi et al., 2010; Goetz et al., 2015). While competing with hake fisheries through direct fish uptake (i.e., ecological interactions), bottlenose dolphins can notably contribute to the total mortality of hake (Santos et al., 2014). Nevertheless, only a few studies have attempted to quantify the fish biomass removed by these dolphin species. For instance, Bearzi et al. (2010) found the annual biomass of fish removed by fisheries to be about 38 times greater than the fish uptake by the bottlenose dolphin population in W Greek waters. Furthermore, Santos et al. (2014) estimated the predation mortalities of four resident dolphin species of the NE Atlantic area preying upon European hake, with the bottlenose dolphin population having the highest uptake of hake ( $82 \%$ of the removed hake biomass).

Since little is known about how fishing and predation in combination affect the ecology and evolution of individual traits and, in return, alter predator abundance and fishing yields, here we investigate the responses of individual traits and population parameters of the European hake under the prevailing fishing selectivity and predation by the bottlenose dolphin. Gårdmark et al. (2003) theoretically explored the evolutionary responses of the age at first reproduction to densityindependent and density-dependent predation and harvesting with regards to the number of species involved and predation type (i.e., Holling's Type I and II). Other studies investigating the effects of 
fishing and predation have explored these from the perspectives of fisheries assessment and ecoevolutionary feedbacks independently, using approaches that range from individual-based to ecosystem models (e.g., Melián et al., 2011; Allhoff et al., 2015; Kindsvater and Palkovacs, 2017;

Wood et al., 2018; Govaert et al., 2019). In this paper, we use an individual-based model to examine how the competitive interactions of natural predators and fisheries affect individual fish traits as well as population resilience and recovery. Similarly to ecosystem resilience (Holling, 1973), we observe the population resilience as the capacity of the population dynamics and structure to withstand and absorb a disturbance whilst maintaining its main ecological and structural characteristics, while recovery is reflected in the speed of recovery of observed parameters after the disturbance has ceased. While the methodological approach allows us to account for the ecological characteristics of the prey and the co-evolved prey-predator dynamics, we firstly focus our investigation on the potential for FIE under the coupled effects of the size-selective pressures. Then we observe the impact of predation on hake population and fisheries. Lastly, we attempt to understand the dynamics between the predator and fisheries with consideration to the ecoevolutionary feedbacks and disruptive fishing regime.

\section{Material and methods}

\subsection{Individual-based model}

In the attempt to address the current research questions, we used an individual based model (IBM), which is an eco-genetic model encompassing quantitative genetics, evolutionary processes, and the ecological characteristics of the fish species. The IBM approach provides an insight into fish individual variability of life history traits, whilst aiding to overcome the lack of information about the exact gene responsible for shaping the response to size-selective removals in hake growth. Furthermore, it also allows us to observe an evolutionary change in fish life history traits in "fast forward mode". To identify the coupled impact of fishing and predation, we expanded an IBM 
initially developed for the Atlantic cod (Gadus morhua; see Kuparinen et al. 2012, 2014; Kuparinen and Hutchings, 2012 for details) and later parameterized for the European hake (see Jusufovski and Kuparinen, 2014). While the baseline model and parameterization for hake are described extensively elsewhere (see Jusufovski and Kuparinen, 2014), in the following text we provide a brief overview of the main model characteristics with a focus on the novel elements: (i) sizeselective mortality caused by predation and (ii) SSD in hake accounted for through sex-specific differences in asymptotic lengths with an individual-based prediction of the length at which a fish becomes sexually mature.

\subsection{Data collection and model parameterization}

\subsubsection{Hake growth and ecological characteristics}

The model simulates fish growth trajectories described by the von Bertalanffy (1938) equation, which calculates an individual's length at age or time step $t\left(\mathrm{~L}_{\mathrm{t}}\right)$ as: $L_{\infty}-\left(L_{\infty}-L_{0}\right) e^{-K t} . L_{\infty}$ is the asymptotic length of an individual, $K$ is the individual intrinsic growth rate (i.e., the rate at which an individual approaches its $\mathrm{L}_{\infty}$ ), and $L_{0}$ is the fish body length at $\mathrm{t}=0 . L_{0}$ is the same value for all individuals and calculated from obtained data, while the length-weight relationship applied corresponds to values used for the southern hake stock (ICES, 2019). We attained the final model of the growth equation through the log-transformation of $K$ and linear regression as: $\log (K)=-0.511$ $0.0041 L_{\infty}$. For this purpose, we used hake growth parameters through the introduction of 64 unsexed data points, available as published data from Mediterranean study cases (see Jusufovski and Kuparinen, 2014). Information on the biological characteristics and fishing regime of European hake reflects the current state of the southern hake stock of the Bay of Biscay and Iberian waters ICES ecoregion (ICES, 2019). Overall, we did not focus on geographical or stock-specific 
characteristics, but rather prioritized reliability and quality in the choice of data and information that is representative for the fish species in general.

Assuming that quantitative traits are defined by a large number of loci with a small additive effect (Roff, 2002), we describe the genotype of each individual with 20 loci, assigning a value of 1 or 0 to each locus. Therefore, summing the values for the loci gives the genotypic value of an individual, ranging from 0 (minimum value) up to 20 (the maximum value). The genetic diversity then corresponds to the range of genotypic values observed with respect to the set conditions and parameters (see further explanation of the tested scenarios in the section Simulation design). Through sexual reproduction, parental genotypic information is transferred to the offspring in accordance with the basic Mendelian laws of inheritance. The phenotype is then based on the individual's genotype, to which phenotypic variation (i.e., normally distributed random noise with mean zero) is added to account for phenotypic plasticity, whilst remaining within the realistic values of heritability (0.2-0.3 for fish species; Mousseau and Roff, 1987). After the genotype is transferred to the phenotype (i.e., $\mathrm{L}_{\infty}$ ), $K$ is then predicted through the strong negative correlation between $K$ and $L_{\infty}$. The maximum hake age is set according to Murua (2010), so that all individuals above 12 years of age have a $100 \%$ probability of dying.

Each individual goes through basic ecological processes depicted in Figure 2. To account for SSD among hake males and females, $L_{\infty}$ is increased by $41 \%$ for female hake, a value representing the discrepancy between the female and male $L_{\infty}$ and calculated using the $R L$ ratio $=L_{m a t} / L_{\infty}$. As male and female hake sexually mature at different lengths or $L_{m a t}$ (i.e., length at maturity), $L_{\infty}$ was calculated separately for each sex, applying the average value of $R L(0.51)$ obtained from the hake dataset. The male and female $L_{m a t}$ applied for the calculation of the percentage difference in $L_{\infty}$ was 32 and $45 \mathrm{~cm}$, respectively (Cerviño, 2014). Apart from the average $R L$ value used as an initial individual value in all simulations (see Table 1), with each time step and for each individual, the $R L$ is attainted based on the individual's $L_{m a t}$ and $L_{\infty}$ values. During each reproduction event, sexually 
mature male and female hake are randomly selected and mated, with the sex of the offspring being assigned by a Bernoulli trial $(\mathrm{p}=0.5)$. Egg production depends directly on female weight, which is derived from the length-weight relationship, and the average recruit-per-spawner value attained through available information on recruitment and the spawning stock biomass (Jusufovski and Kuparinen, 2014). Juvenile survival is determined by a baseline juvenile mortality rate with a probability of survival set to $10 \%$, which also takes into account the known cannibalism in hake (Murua, 2010). Each juvenile is then assigned its own density-dependent growth (for further details, see Jusufovski and Kuparinen, 2014).

Other ecological processes included in the model are density-dependent growth and three sources of natural mortality (Fig. 2). The density-dependent growth of each individual diminishes the growth by $50 \%$ each time the fish population exceeds $90 \%$ of its carrying capacity (see Jusufovski and Kuparinen, 2014 for a detailed description and logistic equation). Instantaneous natural mortality or $M$ (for individuals older than two years) and mortality due to the cost of reproduction or $M_{r c}$ (only for sexually mature individuals) are estimated through parameterization and both are applied equally to male and female hake (Table 1). The fate of each individual is then decided using a Bernoulli trial at each time step.

Fishing is described through a logistic selectivity curve with $L_{50}$ (the length at which $50 \%$ of the population is retained) set at $26.4 \mathrm{~cm}$ based on the prevailing fishing regime (ICES, 2019; Table 1). Only individuals older than three are fished, since at this age, hake have reached or are well over their permitted minimum landing size (MLS).

\subsubsection{Introduction of predation}

The predator population is calculated on a population level using a modification of the Rosenzweig-MacArthur prey-predator model (Rosenzweig and MacArthur, 1963). Depending on 
the Holling's functional response (Holling, 1959) used in the prey equations, the predator equations

248 yield the value of the predator density (p) at each time step $t$ as:

$$
p_{t}=p_{i} e^{e_{p} a_{p} n_{t} /\left(1+h_{p} a_{p} n_{t}\right)-d_{p}}
$$

250 in the case of FRII, while in FRIII, $p_{t}$ depends on:

$p_{t}=p_{i} e^{\left(e_{p} a_{p} n_{t}\right)^{2} /\left(1+\left(h_{p} a_{p} n_{t}\right)^{2}\right)-d_{p}}$

252 where $p_{i}$ is the predator's initial density set for the first time step (see Table 1), after which it 253 becomes the value of $p_{t-1}$ for all subsequent time steps. $p_{t}$ depends on $n_{t}$ or the prey population 254 density attained as a quotient of the number of prey at time $t\left(\mathrm{~N}_{\mathrm{t}}\right)$ and the prey's carrying capacity 255 (CC) at each time step. $e_{p}$, or the predator's assimilation efficiency, the attack rate $\left(\mathrm{a}_{\mathrm{p}}\right)$, and handling time $\left(h_{p}\right)$ are fixed values estimated through parameterization. In turn, the quantity of fish eaten or, more precisely, the probability of an individual being eaten $\left(\mathrm{p}_{\text {eat }}\right)$ is introduced at an individual level 258 and given as:

$p_{\text {eat }}=a_{p} p_{t} /\left(1+h_{p} a_{p} n_{t}\right)$

when FRII is applied and

$p_{\text {eat }}=a_{p} p_{t} n_{t}^{(2-1)} /\left(1+\left(h_{p} a_{p} n_{t}\right)^{2}\right)$

262 in the case of FRIII. $p_{t}$ in both equations denotes the predator population density calculated by equations (1) and (2) for FRII and FRIII, respectively. The functional responses are used here as the probability of a prey fish being eaten in order to account for any uncertainty brought about by intraand interspecific competition of the predator.

Predation is applied across the hake size range from 21 to $51 \mathrm{~cm}$, set according to the average 268 Ibero-Atlantic waters (Saavedra, 2017). The predator parameters $a_{p}, h_{p}$, and $d_{p}$ were estimated 269 (Table 1) and compared to species-specific information on the generation time and dietary requirements from published research on wild and captive bottlenose dolphins (Kastelein et al., 271 2003; Lockyer, 2007; Santos et al., 2014; Saavedra, 2017; Spitz et al., 2018). Since the diet 
composition of the bottlenose dolphin is catholic (Santos et al., 2007; 2014) and its feeding is opportunistic, this is accounted for in the estimation of $h_{p}$. The applied value of the predator's assimilation efficiency $\left(e_{p}\right)$ is in accordance with the observed range of values for toothed whales, i.e. 0.90-0.95 (Lockyer, 2007). Prey and predator population parameters ( $\mathrm{p}_{\mathrm{i}}, \mathrm{N}_{\mathrm{i}}$ and C) are estimated through parameterizations (see Table 1) and set in such a manner that they allow for stable prey-predator dynamics throughout the simulation.

\subsubsection{Simulation design}

In order to observe and detect the independent and coupled effects of fishing and predation, as well as the eco-evolutionary feedbacks under these effects, we formed eight different scenarios (Figure 3). Among the tested scenarios, those without predation and a sex-specific difference in $L_{\infty}$ were simulated as reference scenarios. The scenarios used for the comparative approach are chosen with the focus on the independent and joint impacts of predation and fisheries, rather than the effect of the ecological characteristics of the prey. As the stabilization of prey-predator dynamics is timeconsuming (a total of 3000 time steps), to minimize the computation time, we recorded a priori the adapted hake populations for each scenario. The adapted populations were recorded during the last 150 time steps of a 3000 time step simulation based on the confirmation of stabilization gained through preliminary simulations (output and visual confirmation using graphs). Then, to test the scenario, we used the recorded populations to run simulations for 600 time steps in total and simulated 30 runs for each scenario in order to obtain the representative outcomes of the individual and population parameters. During these simulations in all predation scenarios, predation was applied continuously, while in all eight scenarios, fishing was introduced at the $400^{\text {th }}$ time step. In this manner, we could effectively distinguish the impact of predation, fishing, and evolutionary processes. After the fishing period, we observed effects of the given pressures during the recovery 
time until the end of the simulation. All simulations were performed in R Program v3.6.1 (R Core Team, 2019).

During the simulation testing stage, the introduction of fishing with an intensity of 0.15 and the duration of 100 time steps revealed that each scenario had a different threshold for the fishing duration (Figs S1-S3 in the Supplementary material). In other words, prey and predator population resilience as well as post-fishing recovery were affected by the total mortality applied to hake. The scenarios without predation demonstrated the highest resilience, enduring 100 time steps of fishing, followed by a successful recovery. The reference scenarios had a lower resilience of 75 time steps for the fishing duration, while the FRII scenarios endured 35 time steps of fishing. The FRIII predation scenarios were the least resilient and could only endure 30 time steps of fishing. There was no difference between non-evolutionary and evolutionary scenarios in the maximum sustained duration of the fishing period. For a balanced scenario design, we further applied exactly 30 time steps of fishing to investigate the ecological and evolutionary feedbacks under the coupled effects of fishing and predation. All outputs (incl. Supplement) represent average values of extracted parameters pulled across all 30 simulations for each scenario. In the results, we observe different aspects of predation, fisheries, evolution, and SSD on hake growth, maturity, genotypic diversity and demographic parameters with the regards to their implication for hake recovery and resilience. Firstly, we explore the coupled effects of predation and fishing with respect to FIE alone focusing on the differences between the evolutionary and non-evolutionary scenarios. Secondly, we explore the impact of predation on hake survival as well as how predation affects the fish size availability to fisheries. Lastly, we observe the interactions between the predator and hake fisheries with respect to evolutionary processes, and their implications for predator survival and fishing catches. 


\subsection{Potential for FIE under the coupled effect of predation and fishing}

Overall results between the evolutionary scenarios and their non-evolutionary versions (e.g., the evolutionary and non-evolutionary scenarios without predation and with SSD, and so on) indicate mainly minor discrepancies for the stage of initial introduction of fisheries (presented in the Supplement). In the individual parameters for hake such as asymptotic length $\left(\mathrm{L}_{\infty}\right)$ and intrinsic growth rate (K), all non-evolutionary scenarios reach higher and lower scale values, respectively, than the same scenarios with evolution (Figs S1a and c). Similar responses in $L_{\infty}$ and $K$ are observed in simulations where an identical duration of fishing was applied (Figs $4 \mathrm{a}$ and b). More precisely, the impact of evolutionary processes in achieving the maximum length and its effect on growth rate work in favor of a higher growth rate per time step (age). Furthermore, in simulations with different and identical fishing durations, the evolutionary scenarios demonstrate continuously increasing and decreasing trends in all evolutionary scenarios of $L_{\infty}$ and $K$, respectively (Figs S1a, c and Figs 4a, and $K$ indicate that the ecological characteristics of hake (SSD, lifespan, and reproduction) in combination with evolutionary processes notably delay the stabilization of these individual parameters, despite the hake populations applied for each scenario being fully adapted to the respective scenario settings.

The FRIII scenarios demonstrate differences with evolution absent and present in age at maturity (Fig. 5a), affecting the speed of recovery. In the absence of evolution and with FRIII predation present, hake displays a slower recovery to the respective pre-fishing level, while evolutionary processes provide quicker recovery after fishing cessation. In addition, in the absence of evolution, hake displays a tendency for maturity at a younger age in the FRIII scenarios, although no similar effects of evolutionary processes on size at maturity (Fig. 5b) are observed under FRIII predation. In contrast, with only 30 time steps for the fishing period, size at maturity drops slightly (by $\approx 1 \%$ ) 
in the FRII scenarios, while under FRII predation, a similar reduction in age at maturity gradually levels out at its pre-fishing level by the end of the simulation time. However, longer fishing periods applied during the introduction of fishing induce an increase and decrease in the age and size at maturity, respectively, in the FRII scenario, whereas during the reference and no-predation scenarios (Figs S1b and d), age and size at maturity do not return to their pre-fishing values within the 170 time steps of the recovery period. The reference scenarios, as well as the scenarios without predation, endure the longest fishing periods (75 and 100 time steps in the reference and nopredation scenario, respectively); this indicates that longer fishing periods have a higher potential to induce persistent phenotypic changes (e.g., a long-term decrease or increase in the age and size at maturity) when hake SSD is unaccounted for.

The observed cumulative number of juveniles compared to the present genotypes suggests different genotypic range values among all scenarios (Figs S2 and 5c). Regardless of the applied fishing duration, a wider genotypic range is present in all evolutionary scenarios, as opposed to their respective non-evolutionary versions, which indicates a lower genotypic range due to the absence of sexual reproduction. When a longer fishing period is applied during the introduction fishing (Fig. S2), the range of genotypic values widens in the no-predation scenarios without evolution, while all FRII scenarios, as well as the evolutionary FRIII scenario, exhibit higher numbers of hake juveniles among lower genotypic values when compared to the same scenarios with a fishing period having 30 time steps. While the genotypic values of the current approach translate directly to phenotype, or more precisely to body size, the genotypic trends observed are not reflected in the age-size distribution among evolutionary and non-evolutionary scenarios, meaning that the higher age-size ranges are not present in the evolutionary scenarios, as would be expected (Fig. 6). However, one exception exists where, under the conditions of absent evolutionary processes, the range of the average size at age is slightly higher in the non-evolutionary FRIII scenario than its evolutionary version (S7 and S8, respectively, in Fig. 6). 
Among population parameters, recruitment, and biomass with respect to the carrying capacity (BM to CC) show a discrepancy between the FRIII scenarios in which evolutionary processes are present and absent (Figs 7a-b). The FRIII evolutionary scenario exhibits higher scale values for these parameters than the non-evolutionary scenario, which suggests higher hake survival due to the survival of favorable genotypes (i.e., evolutionary rescue). A similar discrepancy between evolutionary and non-evolutionary FRIII scenarios is observed in recruitment when a longer fishing period is applied (S3a), where no-predation and reference scenarios indicate delayed or impeded recovery to their respective pre-fishing levels. Although not presented in the Supplement, other population parameters such as prey abundance and BM to $\mathrm{CC}$ exhibit the same trend in reference scenarios and scenarios without predation in the presence of evolutionary processes and a longer fishing period. Hake population level parameters (i.e., BM to CC, recruitment) in the FRIII scenarios show a reciprocal relationship between hake numbers and predator density (Figs S3d and 8c), where higher hake biomass do not increase FRIII predator density in the presence of evolution, although there are no differences in recovery among evolutionary and non-evolutionary FRIII scenarios. While evolutionary rescue supports a higher hake biomass, this occurs through the survival of prey sizes that are elusive to an FRIII predator, which otherwise thrives in the absence of an evolving prey. These trends in hake abundance with evolution present support higher fishing catches in the evolutionary FRIII scenario. While the presence or absence of evolutionary processes does not affect the prey-predator density ratio among FRII and FRII scenarios (Figs S3c and 8b), the female-male ratio of hake captures some discrepancies between non-evolutionary and evolutionary scenarios of no-predation and reference scenarios. FRII and FRIII scenarios show similar responses to the fishing period with respect to the absence and presence of evolution, although there is a slight delay in response to fishing in the case of FRIII predation. 


\subsection{Impact of predation mortality on hake survival and fisheries}

The discrepancy in population resilience observed in the simulation testing stage is most evident among scenarios with and without predation, where hake is more susceptible to demographic collapse under predation, especially in the FRIII scenario due to the lowest resilience of only 30 time steps (Figs S1 and S3). Independent of fishing duration, most individual and population parameters of hake demonstrate different scale values due to the trait-mediated effects of predation (Figs S1 and S3, as well as Figs 4-5 and 7-8). Contrary to all scenarios without predation, $L_{\infty}$ shows distinctly higher values under the effect of predation (Figs S1a and 4a), which is reflected as a higher $K$ in the absence of predation (Figs S1c and 4b). As the increasing trend in $L_{\infty}$ and the decreasing trend in $K$ are also present in all scenarios without predation, this suggests that the density-dependent parameters applied in all the scenarios contribute to the slow adaptation of these parameters (in addition to evolutionary processes and hake ecological characteristics). The reduced somatic growth rate under predation is further reflected in the lower age at maturity due to potentially higher allocation to reproduction under predation pressure, whereas reference and nopredation scenarios demonstrate maturity at an older age (Figs S1b and 5a). While all predation scenarios indicate lower somatic growth, size at maturity is unaffected by the presence of predation, with a slightly higher size at maturity in the FRII scenarios than the FRIII scenarios during the prefishing period (Figs S1d and 5b).

\section{Both predation types exhibit strong overcompensation in age and size at maturity with fishing} cessation, due to the release of fishing pressure (Figs 5a and b). For both age and size at maturity, the recovery is faster in all scenarios without predation but with SSD accounted for. In age at maturity, recovery under the reference and FRIII scenarios occurs within a narrow time period, whereas FRII scenarios prolong the recovery the most. Size at maturity more distinctly demonstrates the differences in recovery among scenarios, where the no-predation scenarios are followed by the FRIII, FRII, and reference scenarios. However, with a longer fishing period in the 
reference and the no-predation scenarios (Figs S1b and d), these individual parameters exhibit a strong phenotypic shift in the absence of predation. Comparing the two predation types, the FRIII scenarios allow for quicker recovery, indicating a lesser negative impact than FRII predation, although this could be partly implied by the slightly longer fishing period applied in the FRII scenarios.

Predation mortality and the prey size selectivity shape the genotypic diversity (Fig. 5c) and demographic structure of the hake population (Fig. 6). Reference scenarios demonstrate a very narrow range of genotypes in comparison to the genotypic range values driven by the sex-specific difference in $L_{\infty}$ and predation size selectivity. This strengthens the importance of the size discrepancy among hake females and males, and also suggests that predation drives genotypic diversity in hake, which in return reflects the wider range of the age-size distribution (Fig. 6) in all the predation scenarios. In comparison to the reference scenarios (S1-S2 in Fig. 6), the scenarios without predation (S3-S4 in Fig. 6) show an age-size distribution skewed towards larger females. However, the average size of hake is clearly higher in the FRII and FRIII scenarios (S5-S8 in Fig. 6) than in all the scenarios without predation (S1-S4 in Fig. 5). While the size at age 0 (i.e., $\mathrm{L}_{0}$ ) is the same for all the scenarios, the discrepancies are firstly observed in 1- to 2-year-old hake, which are larger in size for S4-S8 than for S2-S3.

\section{Population parameters (BM to CC and recruitment) exhibit strong overcompensation after} fishing cessation in all the predation scenarios (Figs 7a and b), where hake is clearly low in biomass and other abundance-correlated parameters in the presence of predation. The strong fish removal, however, is more pronounced under FRII than FRIII predation, which can be explained by the higher efficiency of an FRII predator in consuming prey at a lower prey density than an FRIII predator, particularly as prey density in the current IBM is solely dependent on prey abundance.

While biomass levels are lower in the reference and all the predation scenarios, in the no-predation scenarios, biomass exceeds the carrying capacity during the pre-fishing and recovery periods. Such 
levels of biomass suggest weaker density-dependent processes in the conditions of the scenarios without predation, which with the absence of top-down control allow the hake population to outgrow its own carrying capacity. During the pre-fishing period, FRII additionally induces greater fluctuation in all population parameters, regardless of fishing duration (Figs S3a and 7a-b). However, during the recovery period, all the presented population parameters demonstrate the same trend of recovery among scenarios as the size at maturity, where the no-predation scenarios allow for the fastest recovery, followed by the FRIII and FRII scenarios, and lastly the reference scenarios. The order of scenarios showing the fastest to the slowest recovery changes as the duration of the fishing period is increased, as FRIII scenarios now enable faster recovery in recruitment, followed by FRII scenarios, which show a delayed reduction in numbers towards the end of simulation time (Fig. S3a). Furthermore, all scenarios without predation notably slow down the recovery in recruitment, while in the absence of hake, SSD and predation recovery (i.e., reference scenarios) is completely disabled.

\section{The ratio of female to male hake exhibits different responses to fishing depending on the} presence or absence of predation, particularly when observed within the overlapping time frame of fishing and predation (Fig. 7c). Reference scenarios as well as scenarios without predation exhibit a similar trend of a delayed response to fishing, where the proportion of hake males removed by fisheries increases by the end of the fishing period. Contrary to this, FRII and FRIII predators demonstrate different sex (size) selectivity during the fishing period, where an FRII predator increasingly selects hake females towards the middle of the fishing period and then shifts to male hake as fishing ends. An FRIII predator consumes more males as fishing starts, but this ratio of hake sexes gradually shifts towards hake females and then fluctuates around the middle towards the cessation of fishing. Furthermore, the predation types, with their respective targeted prey size, reveal the dynamics of predation and fisheries, suggesting a higher intensity of competition between fisheries and FRII predators. Particularly in case of the FRIII evolutionary scenario, the prey size 
selectivity of predation is reciprocal to the size selectivity of the fisheries. When comparing Figure $7 \mathrm{c}$ with the same graph for a longer fishing period (S3b), the comparison of hake sexes targeted by fisheries and predation is only possible among the scenarios with the two longest durations of the fishing period, meaning the reference scenarios and the scenarios without predation. The reference scenarios with a longer fishing period continue the trend observed in the reference scenarios under a short fishing period, where the proportion of female and male hake continues to fluctuate, with increasingly greater oscillations following each shift from one sex to the other (Fig. S3b). When comparing no-predation scenarios with short and long fishing periods, the proportions of hake males and females removed by the fisheries show a similar trend as in the reference scenarios, but with much lower oscillations.

\subsection{Predator-fisheries interactions: bottlenose dolphin survival and fishing catches}

The dynamic interactions between bottlenose dolphins and fisheries are mainly steered by the availability of hake to each competitor. While the absence of a natural competitor provides a higher gain for fisheries, the fishing catches decrease as the fishing period progresses, with catch slopes becoming steeper in all scenarios (Fig. 8a). The steepest decrease in catches is observed in the reference scenarios, which fall under the catches achieved in the conditions of the evolutionary FRIII scenario by the end of the fishing period. This demonstrates that incorporating key ecological parameters associated with the trait selected by fisheries (i.e., size), as well as predation mortality, slows down the potential depletion of fish. As observed in the hake population parameters (Figs 7ab), as well as in the female-male ratio of hake (Fig. 7c), the most intensive fish removal when comparing the two types of predation is noted in FRII predation, which also reduces fishing catches the most. However, even though predation decreases fishing catches, the smoother catch slope observed in the evolutionary FRIII scenario (Fig. 8a) suggests a lower level of unsustainable fisheries removals in the long term. 
Considering the competitive interaction between predators and fisheries, the prevailing fishing

494 regime exerts a negative indirect effect on predator density through prey-predator interactions (Figs $8 \mathrm{~b}$ and $\mathrm{c})$. More precisely, fishing reduces the predator density in both predation scenarios, which is also reflected in the overcompensation of the prey-predator density ratio after the cessation of fishing (Fig. 8b), particularly in the FRII scenarios with a longer fishing period (Fig. S3c). While an FRII predator achieves a higher density level through the co-evolved prey-predator interaction and more efficient consumption of prey, FRIII predator density benefits less from such interaction, particularly if evolutionary processes are accounted for (Fig. 8c). Interestingly enough, the preypredator density ratio and particularly, the predator density of the evolutionary FRIII scenario demonstrates micro-oscillations between the time steps. In comparison to predation, the removal of hake by fisheries is significantly higher in intensity (observed in hake population parameters) than hake removal by bottlenose dolphins, which impacts on predator survival more profoundly than predators affect the fisheries gain due the absence of other target and prey species (Fig. 8c). Moreover, with a slightly longer fishing period applied in the FRII scenarios (Fig. S3d), predator density does not fully recover to its pre-fishing levels, with or without evolutionary processes in the prey.

\section{Discussion}

\subsection{Specific conditions dictate the potential for FIE under coupled size-selective pressures}

The coupled effects of predation and fishing have diverse implications for a range of fish lifehistory traits (e.g., K, size and age at maturity), with one trait being more susceptible to evolutionary change than another under specific conditions: this dictates the resilience and stability of observed hake parameters, as well as affecting the speed and pattern of recovery in the parameters. These specific conditions are identified here as the presence or the absence of SSD in hake, the duration and intensity of both size-selective pressures, as well as the predation type. Among the individual hake parameters, $L_{\infty}$ and $K$ show resistance towards an evolutionary shift, as 
the ecological characteristics of hake and the density-dependent processes slow down the stabilization of these parameters during the evolutionary scenarios. This can be explained by the formulation of SSD incorporated directly in hake $L_{\infty}$, which, in the presence of all other mentioned conditions, prolongs the time needed for the stabilization of $L_{\infty}$ and, consequently, $K$. Furthermore, as $L_{\infty}$ is the only evolving trait, the evolution in other life-history traits is not as affected by SSD due to the phenotypic rather than genetic correlations among $L_{\infty}$ and other traits. As SSD in fish species is reflected in higher growth rate in males, which reach maturity earlier than females, an improved approach to the description of SSD would be to introduce additional and more reliable sex-specific data on hake growth parameters.

The length of the fishing period, removal intensity, and predation type appear crucial in inducing very persistent alterations in size and age at maturity. While age at maturity shows some resilience to the phenotypic shift in the FRII predation scenarios, size at maturity slightly drops after the cessation of fishing in the same scenarios. With a longer fishing period, the evolutionary change for both individual parameters becomes obvious in all scenarios without predation and SSD accounted for, while age at maturity under the FRII scenarios also shows a lack of recovery to its pre-fishing level. A longer fishing period applied in the reference and no-predation scenarios, as well as FRII scenarios, indicates that fishing duration is pivotal to inducing more pronounced shifts in these individual parameters. This is corroborated by studies on exploited stocks that demonstrate a delayed evolutionary response to fishing after a longer period of exploitation (Devine et al., 2012). Fish species naturally prone to early maturation schedules have demonstrated a higher potential for reduced size at maturity under fishing pressure (Landi et al., 2015). This can only partly explain the decrease in size at maturity of hake in the FRII scenarios after fishing cessation, since the expected decrease in age at maturity did not occur within the same scenario settings. Fishing duration might not be enough to explain the observed alterations in size and age at maturity, as the overall intensity of size-selective removal caused by predation and fishing ultimately contributes to the direction and 
magnitude of their responses. For predation pressure, the predation type is associated with the predation intensity owing to the differences in consumption patterns between the two predation types. The difference in the intensity of size-selective removal between the two predation types supports the higher potential for FIE in the mentioned parameters when the FRII predation type is applied. However, while the currently prevailing fishing size selectivity in synergy with predation removal does not impoverish the genotypic diversity of hake, as observed in other fish species experiencing size-selective removals (see Marty et al., 2015), the ensured phenotypic diversity (owing to the phenotypic variation added to the genotypic values) could mask the potential evolutionary shifts in individual life-history traits. In this case, the potential for adaptive phenotypic plasticity in hake has minimized the impact of evolutionary feedbacks, which is consistent with other studies addressing the phenotypic adaptations of hake to evolutionary processes under harvesting pressure (Hidalgo et al., 2014). Consequently, intraspecific phenotypic diversity further facilitates population demographic stability (i.e., a wide range of age-size classes) and minimizes the impact of size-selective fishing.

\subsection{The importance of accounting for size-related ecological characteristics}

Hake population parameters demonstrate different responses to predation and fishing depending on the presence or absence of SSD and evolutionary processes, as well as the predation type and fishing period. The impact of predation and fishing is most intensive in the FRII scenarios (with SSD in hake accounted for), while the most negative ecological impact of fishing is noted in conditions where predation and SSD are not accounted for. Evolutionary processes, however, have crucial implications for hake abundance and recruitment in the case of the FRIII predation type, where hake survival increases, despite fishing and predation pressures, through evolutionary rescue. This demonstrates that true adaptive changes in hake life-history traits have the potential to counteract the negative effects of size-selective pressures (see Hendry et al., 2011). At the 
individual and population levels, a short fishing duration and accounting for SSD without predation allows hake to recover faster from fishing than under conditions with predation, which supports the cases arguing for slow or even disabled recovery in some overexploited fish stocks due to high predation mortality (Hutchings and Kuparinen, 2019). With an increase in fishing duration, the implications of accounting for SSD, the presence of predation, and the predation type become more crucial to the speed of recovery in hake population parameters. Without SSD accounted for and predation, recovery is impeded or disabled, although the FRIII predation type enables faster recovery than FRII predation. Here, SSD forms the basis for recovery, which is not surprising considering the important implications of SSD for growth parameters, size and age at maturity, sizeselective mortality, and ultimately, the demographic structure of many fish species (Carroll and Lowerre-Barbieri, 2019; Cerviño, 2014; Keyl et al., 2015). Furthermore, the life-history traits of shared fish prey targeted by predators and fisheries is pivotal in determining to what degree the coexistence of predators and fisheries is possible (Huss et al., 2014).

\subsection{Predator individual variability: implications for fish stock assessments}

Under the condition of a two-species prey-predator interaction, it is not surprising that the predation tested here profoundly impacts on fish biomass and population resilience. The current results, however, should be considered alongside the assumptions of this approach, which does not account for the individual variability, ontogenetic development stage, or catholic diet of the bottlenose dolphin. According to Navarrete and Manzur (2008), individual predator parameters (e.g., body size, diet composition, and per capita prey consumption) are more responsive to changes in prey for a generalist predator. However, with regards to the wide range of prey species, bottlenose dolphins have been known to demonstrate prey species preference when offered a choice (Corkeron et al., 1990). Furthermore, under low availability of other prey species, in small food webs as well as in the case of predator specialization to feed on specific prey species (Pettorelli et 
al., 2011), the factors associated with opportunistic feeding in bottlenose dolphins can be less relevant in the presence of high intra- or interspecific competition. In the absence of individual variability, predation types provide a source of ecological complexity directing the response of predator parameters to fishing. Thus, with the increased level of ecological complexity from FRII to FRIII, the competition between predators and fisheries decreases. Here the consumption pattern of predators is of high importance in fish stock assessments, not just for the quantification of predation but also to avoid negative indirect effects of fisheries on marine trophic links and the environment. Moreover, as the evolving prey can facilitate the survival of a non-evolving predator (termed as "indirect evolutionary rescue" by Yamamichi and Miner [2015]), this coincides with the predator population dynamics observed in the FRII predator, but not for the FRIII. In contrast, the reciprocal size selectivity of the prey noted between fisheries and FRIII predation is similar to the fishing strategies targeting all individuals regardless of maturation status, thus reducing the potential for FIE (Ernande et al., 2004). Studies addressing the competitive interactions between marine mammals and fisheries, as well as the impact of high fishing mortality, have revealed that overexploitation is more detrimental to the sustainability of long-term fisheries yields than marine mammals (Garcia et al., 2012; Morissette et al., 2012) or the potential FIE (Hutchings and Kuparinen, 2019). Furthermore, even without a multi-species aspect, the current results predict potential long-term unsustainable outcomes for hake abundance and, consequently, for fisheries in the absence of predation, which is consistent with ecosystem-based studies that predict a decline in fisheries yields due to the lower ecosystem productivity caused by the removal of top predators (Morissette et al., 2010; Roman et al., 2014).

\section{Conclusions}

In this study, we demonstrated how two sources of size-selective mortality in combination with the interplay between ecological and evolutionary processes shape the responses of prey parameters 
at individual and population levels. With respect to this, the duration, intensity, and selected fish

620 size range of both predation pressures have the most prominent implications for the heritability of

621 shifts observed in hake life-history traits, which need to be accounted for when aiming to avoid FIE.

622 As different factors can determine the duration, intensity, and size selectivity of predation and

623 fisheries, the future direction in understanding the prerequisites driving the evolution of individual

624 life-history traits is to investigate which combinations, as well as thresholds of these conditions,

625 have the potential to trigger heritable changes. Since in our study the predation type was found to

626 determine the intensity and size selectivity of predation pressure, future research should address the

627 potential for evolutionary changes with an increase in ecological complexity (i.e., predation type,

628 multi-species, or even ecosystem aspect). According to the outputs of the initial introduction of

629 fisheries, incorporating more than one type of predation in fish stock assessments can aid in setting

630 more reliable limits for harvest yields and rates, weighted against the risks associated with predation

631 intensity as well as potential heritable phenotypic changes. Ultimately, understanding of how

632 predation affects fish availability for fisheries will consequently provide insights into the conditions

633 under which predators indirectly support fisheries or render fishing yields low.

634 While conservative, the current approach applies key prey ecological characteristics and

635 evolutionary processes providing insights into pivotal, baseline mechanisms in the prey-predator

636 dynamics, as well as the ecological interactions between bottlenose dolphins and hake fisheries.

637 With consideration of the implications of SSD for hake fecundity and size-selective mortality, SSD

638 combined with the predation type provides additional insights into the species-specific resilience to

639 and recovery potential under one or multiple size-selective pressures. Such prey-predator dynamics

640 has direct implications for setting sustainable reference points and successful conservation measures

641 to ensure fish survival and the gain of future fisheries. Furthermore, while SSD and FRIII predation

642 selectivity in the presence of evolutionary processes enrich the prey's phenotypic and consequently 
643

genotypic diversity, this can ensure a higher resilience to potential shifts in size at maturity, as it disperses the intensity of size-selective removals by fisheries.

The fishing mortality and selectivity applied here resulted in a profoundly negative ecological impact on hake survival, exceeding the removals and selectivity of predation mortality. Moreover, indirect fishing effects extend to predator survival, as hake consumption by the bottlenose dolphin, and more precisely its prey size selectivity, will depend on the age-size classes available to the predator in the presence of an intensive fishing regime. The dynamics of the fishing regime and predation types of the current study demonstrate how predators adapt their prey size selectivity according to the size selectivity of fishing. The question is whether these predator adjustments to fishing size selectivity will be sufficient to counteract the effects of overexploitation. To answer this, further research is required to address the role of predation from a wider perspective of complex trophic interactions or the ecosystem level. Such aspects are comprehensively included within dynamic ecosystem and individual-based models, which could also explore indirect or even "food-web competition" between bottlenose dolphins and hake fisheries (see ICES, 2015; Wood et al., 2018). However, incorporating individual variability in both prey and predators with the integration of eco-evolutionary feedbacks in a more complex trophic structure is an ambitious step forward to improving the ecosystem approach to fisheries, as well as conservation efforts for natural predators. While similar approaches to the current one do exist, they have not generally accounted for one of the features or processes included in our model. Thus, addressing such a multilayered research question requires a basic approach, where underlying mechanisms can be tested and brought to light. On the other side, holistic approaches to fisheries management demand models that can encapsulate such complexity whilst maintaining the applicability of their outputs to managerial decision-making processes. In line with this, the management of wild fish stocks still remains a multidisciplinary agenda with a strong need for a transdisciplinary approach. 
668

669

670

671

672

673

674

675

676

677

678

679

680

681

682

683

684

685

686

687

688

689

690

691

692

\section{Acknowledgements}

This research was financially supported by the Finnish Cultural Foundation (Grant Nr. 00190412;

DJ), the Academy of Finland (AK), the Natural Sciences and Engineering Research Council of

Canada (AK), and the European Research Council (COMPLEX-FISH 770884; AK). The authors

would like to thank Dr Anssi Vainikka and the two anonymous reviewers for insightful comments and suggestions.

\section{References}

Abrams, P.A., Ginzburg, L.R., 2000. The nature of predation : prey dependent, ratio dependent or neither? TREE 15, 337-341.

Allhoff, K.T., Ritterskamp, D., Rall, B.C., Drossel, B., Guill, C., 2015. Evolutionary food web model based on body masses gives realistic networks with permanent species turnover. Sci. Rep. 5, 1-12. https://doi.org/10.1038/srep10955

Bearzi, G., Agazzi, S., Gonzalvo, J., Bonizzoni, S., Costa, M., Petroselli, A., 2010. Biomass removal by dolphins and fisheries in a Mediterranean Sea coastal area: do dolphins have an ecological impact on fisheries? Aquat. Conserv. Mar. Freshw. Ecosyst. 20, 549-559. https://doi.org/10.1002/aqc.1123

Bearzi, G., Fortuna, C.M., Reeves, R.R., 2008. Ecology and conservation of common bottlenose dolphins Tursiops truncatus in the Mediterranean Sea. Mamm. Rev. 39, 92-123. https://doi.org/10.1111/j.1365-2907.2008.00133.x

Beckerman, A.P., Rodgers, G.M., Dennis, S.R., 2010. The reaction norm of size and age at maturity under multiple predator risk. J. Anim. Ecol. 79, 1069-1076. https://doi.org/10.1111/j.13652656.2010.01703.x

Belgrano, A., Fowler, C.W., 2013. How fisheries affect evolution. Science (80-. ). 342, 1176-1177. 
https://doi.org/10.1126/science.1245490

Bell, R.J., Collie, J.S., Branch, T.A., Fogarty, M.J., Minto, C., Ricard, D., 2018. Changes in the size structure of marine fish communities. ICES J. Mar. Sci. 75, 102-112. https://doi.org/10.1093/icesjms/fsx118

Carroll, J., Lowerre-Barbieri, S.K., 2019. Interactions of dimorphic growth, reproductive behavior, and a size-regulated fishery: A case study using spotted seatrout Cynoscion nebulosus. Mar. Ecol. Prog. Ser. 608, 233-245. https://doi.org/10.3354/meps12795

Cerviño, S., 2014. Estimating growth from sex ratio-at-length data in species with sexual size dimorphism. Fish. Res. 160, 112-119. https://doi.org/10.1016/j.fishres.2013.11.010

Conover, D.O., Munch, S.B., 2002. Sustaining Fisheries Yields Over Evolutionary Time Scales. Science (80-. ). 297, 94-96. https://doi.org/10.1126/science.1074085

Corkeron, P.J., Bryden, M.M., Hedstrom, K.E., 1990. Feeding by bottlenose dolphins in association with trawling operations in Moreton Bay, Australia, in: Leatherwood, S., Reeves, R.R. (Eds.), The Bottlenose Dolphin. Academic Press Inc., San Diego, pp. 329-336.

Crozier, L.G., Hutchings, J.A., 2014. Plastic and evolutionary responses to climate change in fish. Evol. Appl. 7, 68-87. https://doi.org/10.1111/eva.12135

Darimont, C.T., Fox, C.H., Bryan, H.M., Reimchen, T.E., 2015. The unique ecology of human predators. Science (80-. ). 349, 858-860. https://doi.org/10.1126/science.aac4249

De Roos, A.M., Boukal, D.S., Persson, L., 2006. Evolutionary regime shifts in age and size at maturation of exploited fish stocks. Proc. R. Soc. B Biol. Sci. 273, 1873-1880. https://doi.org/10.1098/rspb.2006.3518

DeLong, J.P., Gilbert, B., Shurin, J.B., Savage, V.M., Barton, B.T., Clements, C.F., Dell, A.I., Greig, H.S., Harley, C.D.G., Kratina, P., McCann, K.S., Tunney, T.D., Vasseur, D.A., O’Connor, M.I., 2015. The Body Size Dependence of Trophic Cascades. Am. Nat. 185, 354366. https://doi.org/10.1086/679735 
DeLong, J.P., Luhring, T.M., 2018. Size-dependent predation and correlated life history traits alter eco-evolutionary dynamics and selection for faster individual growth. Popul. Ecol. 60, 9-20. https://doi.org/10.1007/s10144-018-0608-7

Devine, J.A., Wright, P.J., Pardoe, H.E., Heino, M., 2012. Comparing rates of contemporary evolution in life-history traits for exploited fish stocks. Can. J. Fish. Aquat. Sci. 69, 11051120. https://doi.org/10.1139/f2012-047

Domínguez-Petit, R., Korta, M., Saborido-Rey, F., Murua, H., Sainza, M., Piñeiro, C., 2008. Changes in size at maturity of European hake Atlantic populations in relation with stock structure and environmental regimes. J. Mar. Syst. 71, 260-278. https://doi.org/10.1016/j.jmarsys.2007.04.004

Enberg, K., Jørgensen, C., Dunlop, E.S., Heino, M., Dieckmann, U., 2009. Implications of fisheries-induced evolution for stock rebuilding and recovery. Evol. Appl. 2, 394-414. https://doi.org/10.1111/j.1752-4571.2009.00077.x

Ernande, B., Dieckmann, U., Heino, M., 2004. Adaptive changes in harvested populations: Plasticity and evolution of age and size at maturation. Proc. R. Soc. B Biol. Sci. 271, 415-423. https://doi.org/10.1098/rspb.2003.2519

Fraser, D.J., 2013. The emerging synthesis of evolution with ecology in fisheries science. Can. J. Fish. Aquat. Sci. 70, 1417-1428. https://doi.org/10.1139/cjfas-2013-0171

Fryxell, D.C., Wood, Z.T., Robinson, R., Kinnison, M.T., Palkovacs, E.P., 2019. Eco-evolutionary feedbacks link prey adaptation to predator performance. Biol. Lett. 15, 20190626. https://doi.org/10.1098/rsbl.2019.0626

Garcia, S.M., Kolding, J., Rice, J., Rochet, M.-J., Zhou, S., Arimoto, T., Beyer, J.E., Borges, L., Bundy, A., Dunn, D., Fulton, E.A., Hall, M., Heino, M., Law, R., Makino, M., Rijnsdorp, A.D., Simard, F., Smith, A.D.M., 2012. Reconsidering the Consequences of Selective Fisheries. Science (80-. ). 335, 1045-1047. 
https://doi.org/http://dx.doi.org/10.1126/science.1214594

Gårdmark, A., Dieckmann, U., Lundberg, P., 2003. Life-history evolution in harvested populations: The role of natural predation. Evol. Ecol. Res. 5, 239-257.

Gislason, H., Daan, N., Rice, J.C., Pope, J.G., 2010. Size, growth, temperature and the natural mortality of marine fish. Fish Fish. 11, 149-158. https://doi.org/10.1111/j.14672979.2009.00350.x

Goetz, S., Read, F.L., Ferreira, M., Portela, J.M., Santos, M.B., Vingada, J., Siebert, U., Marçalo, A., Santos, J., Araújo, H., Monteiro, S., Caldas, M., Riera, M., Pierce, G.J., 2015. Cetacean occurrence, habitat preferences and potential for cetacean-fishery interactions in Iberian Atlantic waters: Results from cooperative research involving local stakeholders. Aquat. Conserv. Mar. Freshw. Ecosyst. 25, 138-154. https://doi.org/10.1002/aqc.2481

Govaert, L., Fronhofer, E.A., Lion, S., Eizaguirre, C., Bonte, D., Egas, Ma., Hendry, A.P., De Brito Martins, A., Melián, C.J., Raeymaekers, J.A.M., Ratikainen, I.I., Saether, B.E., Schweitzer, J.A., Matthews, B., 2019. Eco-evolutionary feedbacks-Theoretical models and perspectives. Funct. Ecol. 33, 13-30. https://doi.org/10.1111/1365-2435.13241

Griffiths, D., 1975. Prey Availability and the Food of Predators. Ecology 56, 1209-1214. https://doi.org/10.2307/1936161

Heino, M., Beatriz, D., Dieckmann, U., 2015. Fisheries-Induced Evolution. Annu. Rev. Ecol. Evol. Syst. 46, 461-480. https://doi.org/10.1146/annurev-ecolsys-112414-054339

Hendry, A.P., 2016. Key questions on the role of phenotypic plasticity in eco-evolutionary dynamics. J. Hered. 107, 25-41. https://doi.org/10.1093/jhered/esv060

Hendry, A.P., Kinnison, M.T., Heino, M., Day, T., Smith, T.B., Fitt, G., Bergstrom, C.T., Oakeshott, J., Jørgensen, P.S., Zalucki, M.P., Gilchrist, G., Southerton, S., Sih, A., Strauss, S., Denison, R.F., Carroll, S.P., 2011. Evolutionary principles and their practical application. Evol. Appl. 4, 159-183. https://doi.org/10.1111/j.1752-4571.2010.00165.x 
Hernandez-Milian, G., Berrow, S., Santos, M.B., Reid, D., Rogan, E., 2015. Insights into the trophic ecology of bottlenose dolphins (Tursiops truncatus) in Irish waters. Aquat. Mamm. 41, 226-239. https://doi.org/10.1578/AM.41.2.2015.226

Hidalgo, M., Olsen, E., , J., Saborido- Rey, F., Murua, H., Stenseth, N.C., 2014. Contrasting evolutionary demography induced by fishing : the role of adaptive phenotypic plasticity. Ecol. Appl. 24, 1101-1114. https://doi.org/https://doi.org/10.1890/12-1777.1

Holling, C.S., 1973. Resilience and Stability of Ecological Systems. Annu. Rev. Ecol. Syst. 4, 1-23.

Holling, C.S., 1959. The Components of Predation as Revealed by a Study of Small Mammal Predation of the European Pine Sawfly. Can. Entomol. 91, 293-320.

Huss, M., de Roos, A.M., Van Leeuwen, A., Gårdmark, A., 2014. Facilitation of fisheries by natural predators depends on life history of shared prey. Oikos 123, 1071-1080. https://doi.org/10.1111/oik.00839

Hutchings, J.A., Kuparinen, A., 2019. Implications of fisheries-induced evolution for population recovery: Refocusing the science and refining its communication. Fish Fish. 1-12. https://doi.org/10.1111/faf.12424

ICES, 2019. Report of the Working Group for the Bay of Biscay and the Iberian waters Ecoregion (WGBIE). https://doi.org/http://doi.org/10.17895/ices.pub.5299

Jusufovski, D., Kuparinen, A., 2014. Contrasting evolutionary and ecological management objectives in the context of sustainable harvesting. Evol. Ecol. Res. 16.

Kastelein, R.A., Staal, C., Wiepkema, P.R., 2003. Food consumption, food passage time, and body measurements of captive Atlantic bottlenose dolphins (Tursiops truncatus). Aquat. Mamm. 29, 53-66. https://doi.org/10.1578/016754203101024077

Keyl, F., Kempf, A.J., Sell, A.F., 2015. Sexual size dimorphism in three North Sea gadoids. J. Fish Biol. 86, 261-275. https://doi.org/10.1111/jfb.12579

Kindsvater, H.K., Palkovacs, E.P., 2017. Predicting Eco-evolutionary Impacts of Fishing on Body 
Size and Trophic Role of Atlantic Cod. Copeia 105, 475-482. https://doi.org/10.1643/ot-16533

Kuparinen, A., Hardie, D.C., Hutchings, J.A., 2012. Evolutionary and ecological feedbacks of the survival cost of reproduction. Evol. Appl. 5, 245-255. https://doi.org/10.1111/j.17524571.2011.00215.x

Kuparinen, A., Hutchings, J.A., 2012. Consequences of fisheries-induced evolution for population productivity and recovery potential. Proc. R. Soc. B Biol. Sci. 279, 2571-2579. https://doi.org/10.1098/rspb.2012.0120

Kuparinen, A., Stenseth, N.C., Hutchings, J.A., 2014. Fundamental population-productivity relationships can be modified through density-dependent feedbacks of life-history evolution. Evol. Appl.

Landi, P., Hui, C., Dieckmann, U., 2015. Fisheries-induced disruptive selection. J. Theor. Biol. 365, 204-216. https://doi.org/10.1016/j.jtbi.2014.10.017

Lankau, R.A., Strauss, S.Y., 2011. Newly rare or newly common: evolutionary feedbacks through changes in population density and relative species abundance, and their management implications. Evol. Appl. 4, 338-353. https://doi.org/10.1111/j.1752-4571.2010.00173.x

Law, R., 2000. Fishing, selection, and phenotypic evolution. ICES J. Mar. Sci. 57, 659-668. https://doi.org/10.1006/jmsc.2000.0731

Law, R., Grey, D.R., 1989. Evolution of yields from populations with age-specific cropping. Evol. Ecol. 3, 343-359. https://doi.org/10.1007/BF02285264

Law, R., Plank, M.J., 2018. Balanced harvesting could reduce fisheries-induced evolution. Fish Fish. 19, 1078-1091. https://doi.org/10.1111/faf.12313

Lockyer, C., 2007. All creatures great and smaller: A study in cetacean life history energetics. J. Mar. Biol. Assoc. United Kingdom 87, 1035-1045. https://doi.org/10.1017/S0025315407054720 
López, B.D., 2006. Interactions between Mediterranean bottlenose dolphins (Tursiops truncatus) and gillnets off Sardinia, Italy. ICES J. Mar. Sci. 63, 946-951. https://doi.org/10.1016/j.icesjms.2005.06.012

Lowerre-Barbieri, S., DeCelles, G., Pepin, P., Catalán, I.A., Muhling, B., Erisman, B., Cadrin, S.X., Alós, J., Ospina-Alvarez, A., Stachura, M.M., Tringali, M.D., Burnsed, S.W., Paris, C.B., 2017. Reproductive resilience: a paradigm shift in understanding spawner-recruit systems in exploited marine fish. Fish Fish. 18, 285-312. https://doi.org/10.1111/faf.12180

Madin, E.M.P., Dill, L.M., Ridlon, A.D., Heithaus, M.R., Warner, R.R., 2016. Human activities change marine ecosystems by altering predation risk. Glob. Chang. Biol. 22, 44-60. https://doi.org/10.1111/gcb.13083

Marty, L., Dieckmann, U., Ernande, B., 2015. Fisheries-induced neutral and adaptive evolution in exploited fish populations and consequences for their adaptive potential. Evol. Appl. 8, 47-63. https://doi.org/10.1111/eva.12220

Mehault, S., Domínguez-Petit, R., Cerviño, S., Saborido-Rey, F., 2010. Variability in total egg production and implications for management of the southern stock of European hake. Fish. Res. 104, 111-122. https://doi.org/10.1016/j.fishres.2010.03.019

Melián, C.J., Vilas, C., Baldó, F., González-Ortegón, E., Drake, P., Williams, R.J., 2011. Ecoevolutionary Dynamics of Individual-Based Food Webs, in: Advances in Ecological Research. Elsevier Ltd., pp. 225-268. https://doi.org/10.1016/B978-0-12-386475-8.00006-X

Morissette, L., Christensen, V., Pauly, D., 2012. Marine Mammal Impacts in Exploited Ecosystems: Would Large Scale Culling Benefit Fisheries? PLoS One 7. https://doi.org/10.1371/journal.pone.0043966

Morissette, L., Kaschner, K., Gerber, L.R., 2010. Ecosystem models clarify the trophic role of whales off Northwest Africa. Mar. Ecol. Prog. Ser. 404, 289-302. https://doi.org/10.3354/meps08443 
Mousseau, T.A., Roff, D.A., 1987. Natural selection and the heritability of fitness components. Heredity (Edinb). 59, 181.

Murua, H., 2010. The Biology and Fisheries of European Hake, Merluccius merluccius , in the North-East Atlantic, 1st ed, Advances in Marine Biology. Elsevier Ltd. https://doi.org/10.1016/B978-0-12-381015-1.00002-2

Navarrete, S.A., Manzur, T., 2008. Individual- And population-level responses of a keystone predator to geographic variation in prey. Ecology 89, 2005-2018. https://doi.org/10.1890/071231.1

Neubauer, P., Jensen, O.P., Hutchings, J.A., Baum, J.K., 2013. Resilience and recovery of overexploited marine populations. Science (80-. ). 340, 347-349. https://doi.org/10.1126/science.1230441

Ohlberger, J., Thackeray, S.J., Winfield, I.J., Maberly, S.C., Vøllestad, L.A., 2014. When phenology matters: Age - size truncation alters population response to trophic mismatch. Proc. R. Soc. B Biol. Sci. 281, 1-7. https://doi.org/10.1098/rspb.2014.0938

Palkovacs, E.P., Kinnison, M.T., Correa, C., Dalton, C.M., Hendry, A.P., 2012. Fates beyond traits: Ecological consequences of human-induced trait change. Evol. Appl. 5, 183-191. https://doi.org/10.1111/j.1752-4571.2011.00212.x

Palkovacs, E.P., Moritsch, M.M., Contolini, G.M., Pelletier, F., 2018. Ecology of harvest-driven trait changes and implications for ecosystem management. Front. Ecol. Environ. 16, 20-28. https://doi.org/10.1002/fee.1743

Pettorelli, N., Coulson, T., Durant, S.M., Gaillard, J.M., 2011. Predation, individual variability and vertebrate population dynamics. Oecologia 167, 305-314. https://doi.org/10.1007/s00442-0112069-y

Philips, B.L., Brown, G.P., Shine, R., 2010. Life-history evolution in range-shifting populations. Ecology 91, 1617-1627. https://doi.org/https://doi.org/10.1890/09-0910.1 
R Core Team 2019. R: A language and environment for statistical computing. R Foundation for Statistical Computing, Vienna, Austria. https://www.R-project.org/.

Reznick, D. A., Bryga, H. and Endler, J.A., 1990. Experimentally induced life-history evolution in a natural population. Nat. Publ. Gr. 346, 357-359. https://doi.org/10.1038/346357a0

Roff, D.A., 2002. Life history evolution. Sinauer, Sunderland, MA.

Roman, J., Estes, J.A., Morissette, L., Smith, C., Costa, D., McCarthy, J., Nation, J., Nicol, S., Pershing, A., Smetacek, V., 2014. Whales as marine ecosystem engineers. Front. Ecol. Environ. 12, 377-385. https://doi.org/10.1890/130220

Rosenzweig, M.. L.., MacArthur, R.H., 1963. Graphical Representation and Stability Conditions of Predator-Prey Interactions. Am. Nat. 97, 209-223.

Saavedra, C., 2017. Multispecies population modelling of the common dolphin (Delphinus delphis), the bottlenose dolphin (Tursiops truncatus) and the southern stock of European hake (Merluccius merluccius), in Atlantic waters of the Iberian Peninsula. University of Vigo, Spain.

Santos, M.B., Fernández, R., López, A., Martínez, J.A., Pierce, G.J., 2007. Variability in the diet of bottlenose dolphin, Tursiops truncatus, in Galician waters, north-western Spain, 1990-2005. J. Mar. Biol. Assoc. United Kingdom 87, 231-241. https://doi.org/10.1017/S0025315407055233

Santos, M.B., Saavedra, C., Pierce, G.J., 2014. Quantifying the predation on sardine and hake by cetaceans in the Atlantic waters of the Iberian Peninsula. Deep. Res. Part II Top. Stud. Oceanogr. 106, 232-244. https://doi.org/10.1016/j.dsr2.2013.09.040

Scharf, F.S., Juanes, F., Rountree, R.A., 2000. Predator size - Prey size relationships of marine fish predators: Interspecific variation and effects of ontogeny and body size on trophic-niche breadth. Mar. Ecol. Prog. Ser. 208, 229-248. https://doi.org/10.3354/meps208229

Sion, L., Zupa, W., Calculli, C., Garofalo, G., Hidalgo, M., 2019. Spatial distribution pattern of European hake, Merluccius merluccius (Pisces : Merlucciidae), in the Mediterranean Sea. Sci. 
Mar. 83, 000-000. https://doi.org/10.3989/scimar.04988.12A

894 Shuter, B.J., Giacomini, H.C., de Kerckhove, D., Vascotto, K., 2015. Fish life history dynamics: 895 shifts in prey size structure evoke shifts in predator maturation traits. Can. J. Fish. Aquat. Sci. 73, 693-708. https://doi.org/10.1139/cjfas-2015-0190

Spitz, J., Ridoux, V., Trites, A.W., Laran, S., Authier, M., 2018. Prey consumption by cetaceans reveals the importance of energy-rich food webs in the Bay of Biscay. Prog. Oceanogr. 166, 148-158. https://doi.org/10.1016/j.pocean.2017.09.013

Swain, D.P., Sinclair, A.F., Hanson, J.M., 2007. Evolutionary response to size-selective mortality in an exploited fish population. Proc. R. Soc. B Biol. Sci. 274, 1015-1022. https://doi.org/10.1098/rspb.2006.0275

Waples, R.S., Audzijonyte, A., 2016. Fishery-induced evolution provides insights into adaptive responses of marine species to climate change. Front. Ecol. Environ. 14, 217-224. https://doi.org/10.1002/fee.1264

Wood, Z.T., Palkovacs, E.P., Kinnison, M.T., 2018. Eco-evolutionary Feedbacks from Non-target Species Influence Harvest Yield and Sustainability. Sci. Rep. 8, 6389. https://doi.org/10.1038/s41598-018-24555-0

Yamamichi, M., Miner, B.E., 2015. Indirect evolutionary rescue: Prey adapts, predator avoids extinction. Evol. Appl. 8, 787-795. https://doi.org/10.1111/eva.12295

Zhou, S., Smith, A.D.M., Punt, A.E., Richardson, A.J., Gibbs, M., Fulton, E.A., Pascoe, S., Bulman, C., Bayliss, P., Sainsbury, K., 2010. Ecosystem-based fisheries management requires a change to the selective fishing philosophy. Proc. Natl. Acad. Sci. 107, 9485-9489. https://doi.org/10.1073/pnas.0912771107

E-Sources:

Wikipedia Commons: https://commons.wikimedia.org/wiki/File:Merluccius_merluccius_mapa.svg; 
919 European Commission, Fisheries:

937 Table 1. Set values of model parameters $\left(\mathrm{M}=\right.$ natural mortality; $\mathrm{M}_{\mathrm{rc}}=$ natural mortality due to cost 938 of reproduction; $\mathrm{N}_{\mathrm{i}}=$ prey initial population size; $\mathrm{CC}=$ prey carrying capacity; $\mathrm{p}_{\mathrm{i}}=$ predator initial 939 population density; $\mathrm{a}=$ predator attack rate; $\mathrm{e}=$ assimilation efficiency; $\mathrm{d}=$ predator death rate; $\mathrm{h}=$ 940 predator handling time; $\mathrm{F}=$ fishing intensity; $\mathrm{a}, \mathrm{b}=$ fishing selectivity parameters; $\mathrm{L}_{50}=$ length at $94150 \%$ retention). 


\begin{tabular}{|c|c|c|c|c|c|c|c|c|c|c|}
\hline \multirow{7}{*}{ 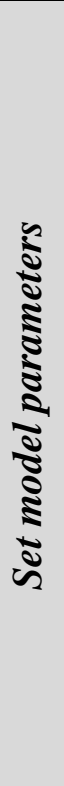 } & \multirow{5}{*}{ 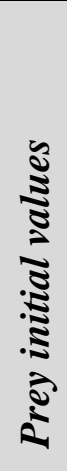 } & Parameters & Values & $\mathrm{Sou}$ & ces & & Parameters & Values & Sou & ces \\
\hline & & $M$ & 0.1 & \multirow{6}{*}{ 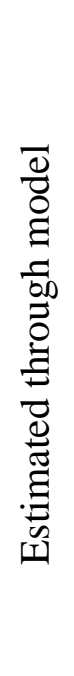 } & \multirow{6}{*}{ 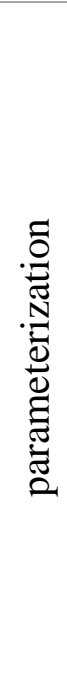 } & \multirow{3}{*}{ 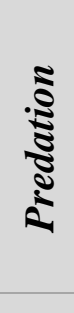 } & $e$ & 0.90 & \multicolumn{2}{|c|}{$\begin{array}{c}\text { Lockyer, } \\
2007\end{array}$} \\
\hline & & $M_{r c}$ & 0.1 & & & & $d$ & 0.06 & \multirow{4}{*}{ 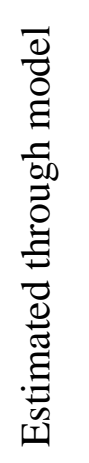 } & \multirow{4}{*}{ 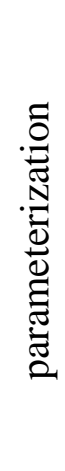 } \\
\hline & & $N_{i}$ & 4000 & & & & $h$ & 0.5 & & \\
\hline & & $C C$ & 6000 & & & & $F$ & 0.15 & & \\
\hline & \multirow{2}{*}{ 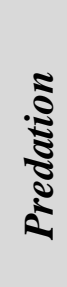 } & $p_{i}$ & 0.3 & & & 这 & $a, b$ & $\begin{array}{r}-10.85 \\
0.411\end{array}$ & & \\
\hline & & $a$ & 0.07 & & & & $L_{50}$ & $24.6 \mathrm{~cm}$ & \multicolumn{2}{|c|}{$\begin{array}{c}\text { ICES, } \\
2019\end{array}$} \\
\hline
\end{tabular}

Figure captions

955

956 Figure 1. The European hake and its native distribution range in European, African, and Asian seas 957 (Wikipedia Commons, user Misigon; ec.europe.eu).

959 Figure 2. Visual presentation of an individual growth trajectory and density-dependent growth (plot 960 A) as well as a stepwise introduction of the size-selective removals by predation (plot B) and 961 fisheries (plot C). In all plots fish body length is plotted against the simulation time steps (T) with 
the curved line depicting the asymptotic growth trajectory (full line denoting the trajectory with evolution and dashed without evolution). In plot A), each individual trajectory is defined by length at maturity $\left(\mathrm{L}_{\mathrm{mat}}\right)$ and maximum theoretical length $\left(\mathrm{L}_{\infty}\right)$. If the hake population density is high, the time left for the individual to grow (i.e., the interval between $\mathrm{T}$ and $\mathrm{T}+1$ ) is reduced by $50 \%$ (adapted from Kuparinen et al., 2012). Plot B) demonstrates the introduction of predation, which is present throughout the entire simulation time (denoted by the green background), selecting only individuals between 21 and $51 \mathrm{~cm}$ of length (denoted by dotted horizontal lines). In plot C), with predation present, fishing is introduced through a narrower time period in the simulation (denoted by the red background), but targeting a range of hake length with a 50\% retention at the length of $26.4 \mathrm{~cm}$ (L50; red dot-dashed horizontal line). The lower limit for the hake size range is set by the age of the individual (> 2) denoted in the red dotted horizontal line, which approximately corresponds to $22-23 \mathrm{~cm}$ of length. However, it is important to note that the actual retention by the fishing gear is described by logistic, asymptotic curve.

Figure 3. Scheme of eight tested scenarios denoted by S1-S8, as follows: S1) non-evolutionary scenario without predation, a sex-specific difference in asymptotic length $\left(\mathrm{L}_{\infty}\right)$, as well as without evolution (reference scenarios); S2) evolutionary scenario without predation and a sex-specific difference in $\mathrm{L}_{\infty} ; \mathrm{S} 3$ ) non-evolutionary scenario without predation; S4) evolutionary scenario without predation; S5) non-evolutionary scenario with FRII predation; S6) evolutionary scenario with FRII predation; S7) non-evolutionary scenario with FRIII predation; and S8) evolutionary scenario with FRIII predation.

Figure 4. Graphs showing the average values of individual hake growth parameters, asymptotic length (a) and the intrinsic growth rate (b). The parameters are plotted against the simulation time on the x-axis, where vertical dashed lines delineate the fishing period of 30 time steps from the prefishing period (up to 399 time steps) and recovery period (431-600). Non-evolutionary and 
evolutionary scenarios are denoted by dotted and bold lines, respectively. Scenarios without predation are depicted in grey, FRII in green, and FRIII in red. Scenarios without predation and a sex-specific difference in $L_{\infty}$ (reference scenarios) are presented in black.

Figure 5. Average values of hake individual parameters showing the age (a) and size at maturity (b), and genotypic diversity (c) with respect to each scenario. Plots a) and b) are plotted against simulation time steps where the fishing period is denoted with vertical, dashed lines (400-430). In plot $\mathrm{c}$ ), the cumulative number $(\mathrm{N})$ of juveniles is plotted against the genotype values. In all plots, the dotted lines denote the non-evolutionary scenarios, whereas the bold lines denote the evolutionary scenarios. All reference scenarios are depicted in black color, while no-predation, FRII and FRIII scenarios are depicted in grey, green and red colors, respectively.

Figure 6. Hake demographic structure based on each scenario. The $\mathrm{x}$-axis denotes the scenarios as: S1) non-evolutionary scenario without predation and a sex-specific difference in $L_{\infty}$ (reference scenario without evolution); S2) evolutionary scenario without predation and a sex-specific difference in $L_{\infty}$ (reference scenario with evolution); S3) non-evolutionary scenario without predation; S4) evolutionary scenario without predation; S5) non-evolutionary scenario with FRII predation; S6) evolutionary scenario with FRII predation; S7) non-evolutionary scenario with FRIII predation, and S8) evolutionary scenario with FRIII predation. Each bar per scenario depicts the average size at age as well as each age category ranging from $0-12$ years. Size at $L_{0}$ (first size bar) is the same for all scenarios and set to $3.9 \mathrm{~cm}$.

Figure 7. Graphs presenting the average values of hake demographic parameters for each scenario, as follows: a) recruitment; b) population biomass with respect to carrying capacity (BM to CC); and c) hake female to male density ratio. Simulation time steps on the $\mathrm{x}$-axis are divided into pre-fishing 
1013 (0-399), fishing (400-430), and recovery periods (431-600) by vertical dashed lines. Scenarios 1014 differ according to the presence or absence of evolution as bold or dotted lines, while a black color 1015 depicts reference scenarios, a grey color depicts scenarios without predation, green with FRII, and 1016 red with FRIII predation scenarios.

1018 Figure 8. Hake and bottlenose dolphin population dynamics under fishing pressure with respect to 1019 each scenario. Average values of the following population parameters are presented: a) caught hake 1020 biomass; b) hake and bottlenose dolphin density ratio; and c) bottlenose dolphin density. Simulation 1021 time steps (x-axis) are divided by vertical dashed lines into pre-fishing (0-399), fishing (400-430), 1022 and recovery periods (431-600), although plot a) only shows the fishing period. Dotted and bold 1023 lines depict non-evolutionary and evolutionary scenarios, respectively, where a grey color denotes 1024 scenarios without predation, green FRII, and red FRIII predation scenarios. Reference scenarios are 1025 denoted in black only in plot a). 


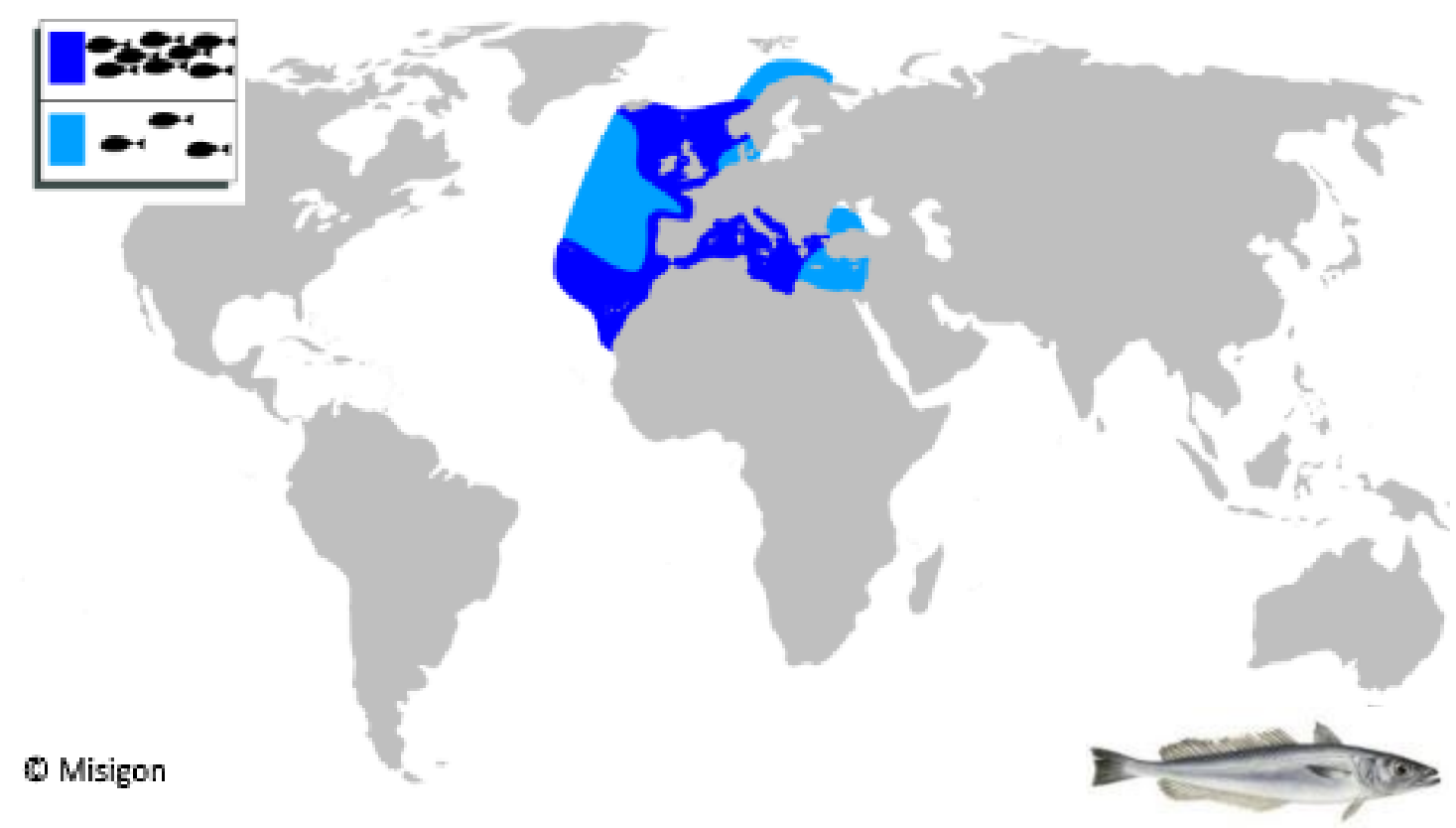

1034 Figure 1. The European hake and its native distribution range in European, African, and Asian seas 1035 (Wikipedia Commons, user Misigon; ec.europe.eu).

1036 
B)

Step 1.

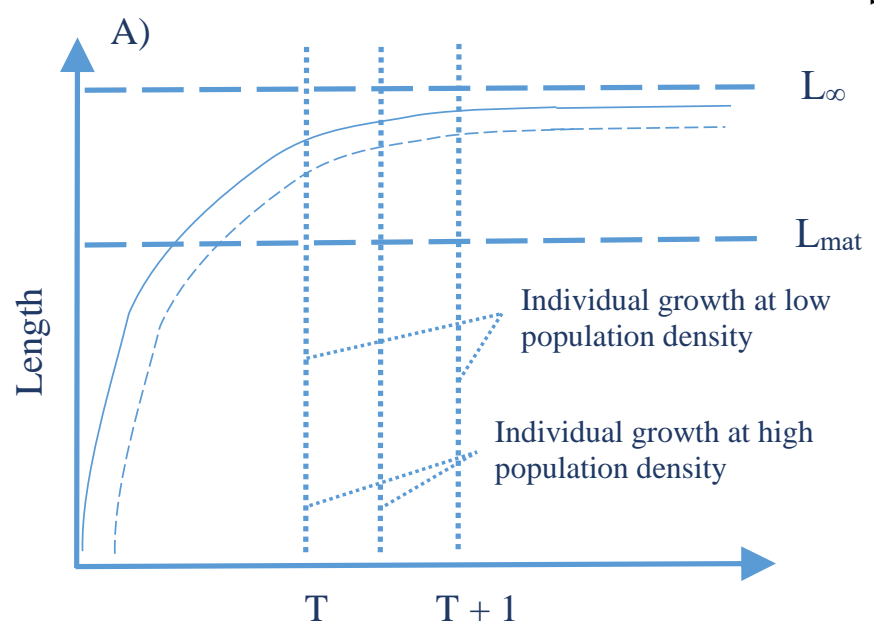

T

Step 2.

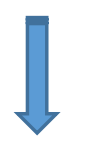

C)

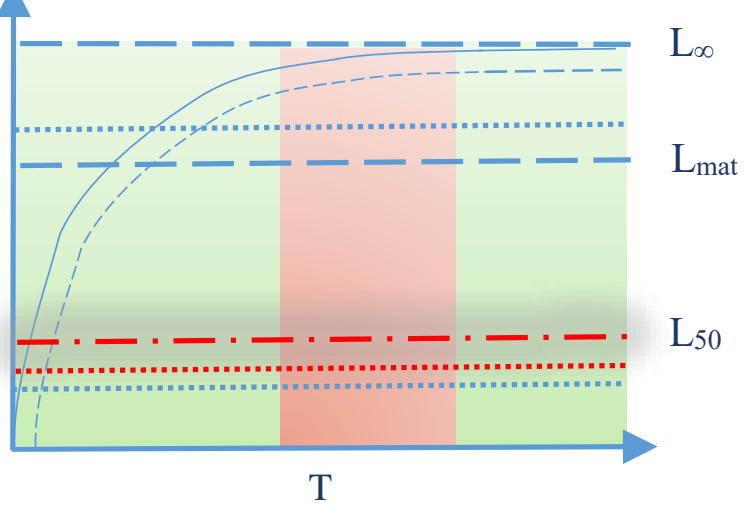

Figure 2. Visual presentation of an individual growth trajectory and density-dependent growth (plot A) as well as a stepwise introduction of the size-selective removals by predation (plot B) and fisheries (plot C). In all plots fish body length is plotted against the simulation time steps (T) with the curved line depicting the asymptotic growth trajectory (full line denoting the trajectory with evolution and dashed without evolution). In plot A), each individual trajectory is defined by length at maturity ( $\left.\mathrm{L}_{\text {mat }}\right)$ and maximum theoretical length $\left(\mathrm{L}_{\infty}\right)$. If the hake population density is high, the time left for the individual to grow (i.e., the interval between $\mathrm{T}$ and $\mathrm{T}+1$ ) is reduced by $50 \%$ (adapted from Kuparinen et al., 2012). Plot B) demonstrates the introduction of predation, which is present throughout the entire simulation time (denoted by the green background), selecting only individuals between 21 and $51 \mathrm{~cm}$ of length (denoted by dotted horizontal lines). In plot C), with predation present, fishing is introduced through a narrower time period in the simulation (denoted 
by the red background), but targeting a range of hake length with a 50\% retention at the length of $107326.4 \mathrm{~cm}$ ( $\mathrm{L}_{50}$; red dot-dashed horizontal line). The lower limit for the hake size range is set by the age of the individual (>2) denoted in the red dotted horizontal line, which approximately corresponds to $22-23 \mathrm{~cm}$ of length. However, it is important to note that the actual retention by the fishing gear is described by logistic, asymptotic curve.

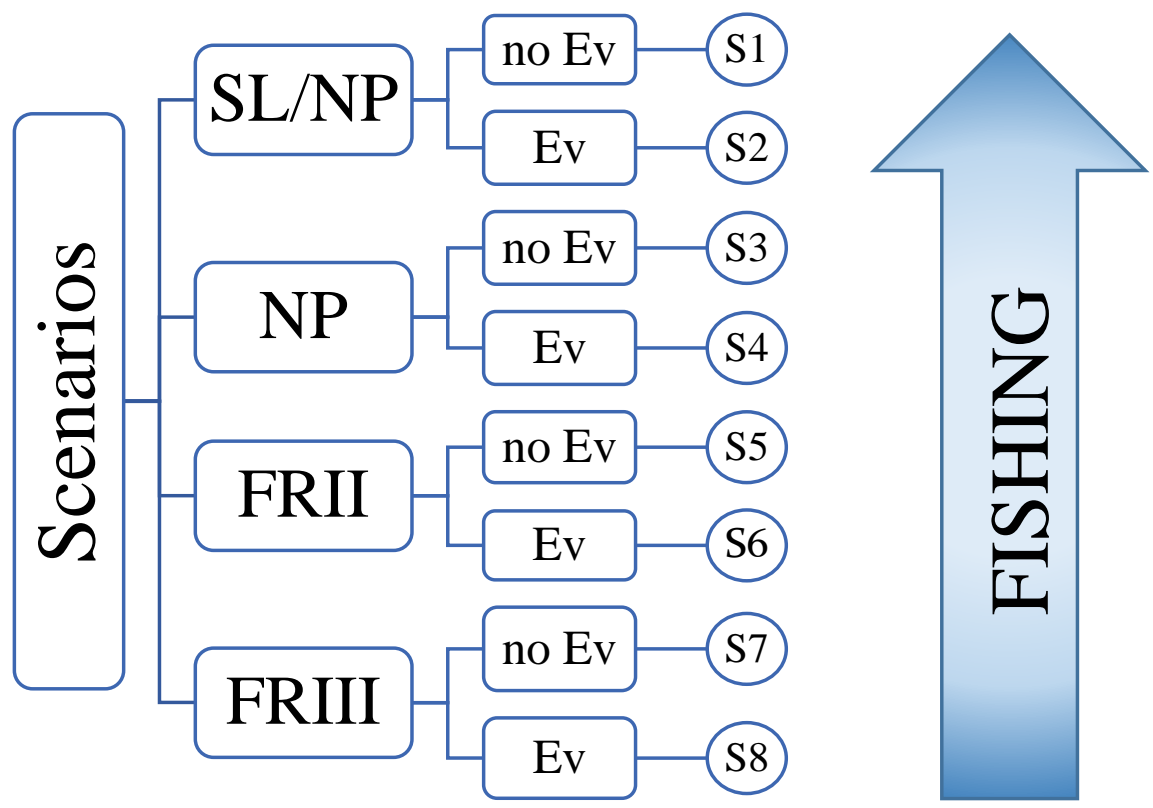

Figure 3. Scheme of eight tested scenarios denoted by S1-S8, as follows: S1) non-evolutionary scenario without predation, a sex-specific difference in asymptotic length $\left(\mathrm{L}_{\infty}\right)$, as well as without evolution (reference scenarios); S2) evolutionary scenario without predation and a sex-specific difference in $\mathrm{L}_{\infty} ; \mathrm{S} 3$ ) non-evolutionary scenario without predation; S4) evolutionary scenario without predation; S5) non-evolutionary scenario with FRII predation; S6) evolutionary scenario with FRII predation; S7) non-evolutionary scenario with FRIII predation; and S8) evolutionary scenario with FRIII predation. 

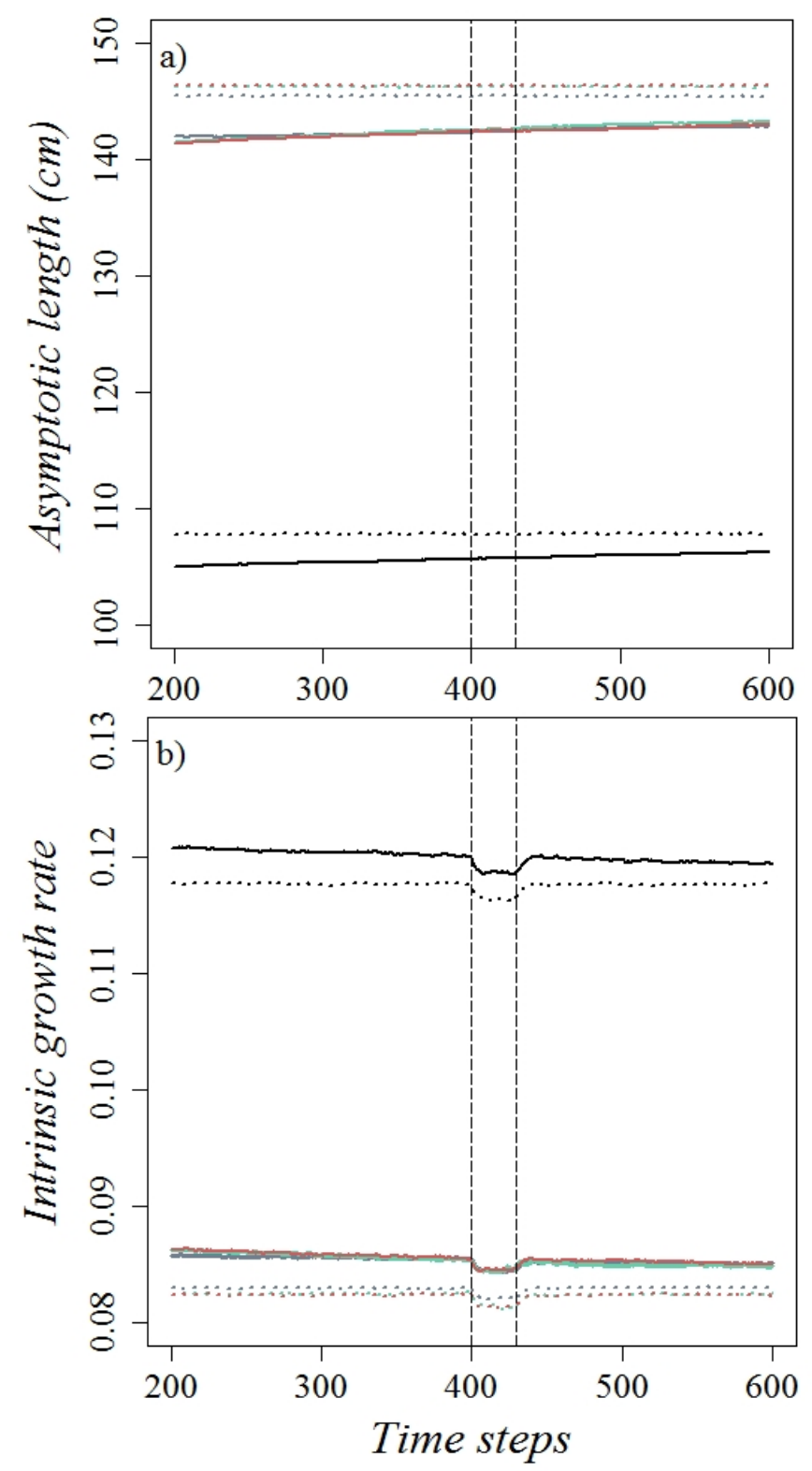

Figure 4. Graphs showing the average values of individual hake growth parameters, asymptotic length (a) and the intrinsic growth rate (b). The parameters are plotted against the simulation time on the $\mathrm{x}$ axis, where vertical dashed lines delineate the fishing period of 30 time steps from the pre-fishing period (up to 399 time steps) and recovery period (431-600). Nonevolutionary and evolutionary scenarios are denoted by dotted and bold lines, respectively. Scenarios without predation are depicted in grey, FRII in green, and FRIII in red. Scenarios without predation and a sex-specific difference in $L_{\infty}$ (reference scenarios) are presented in black. 

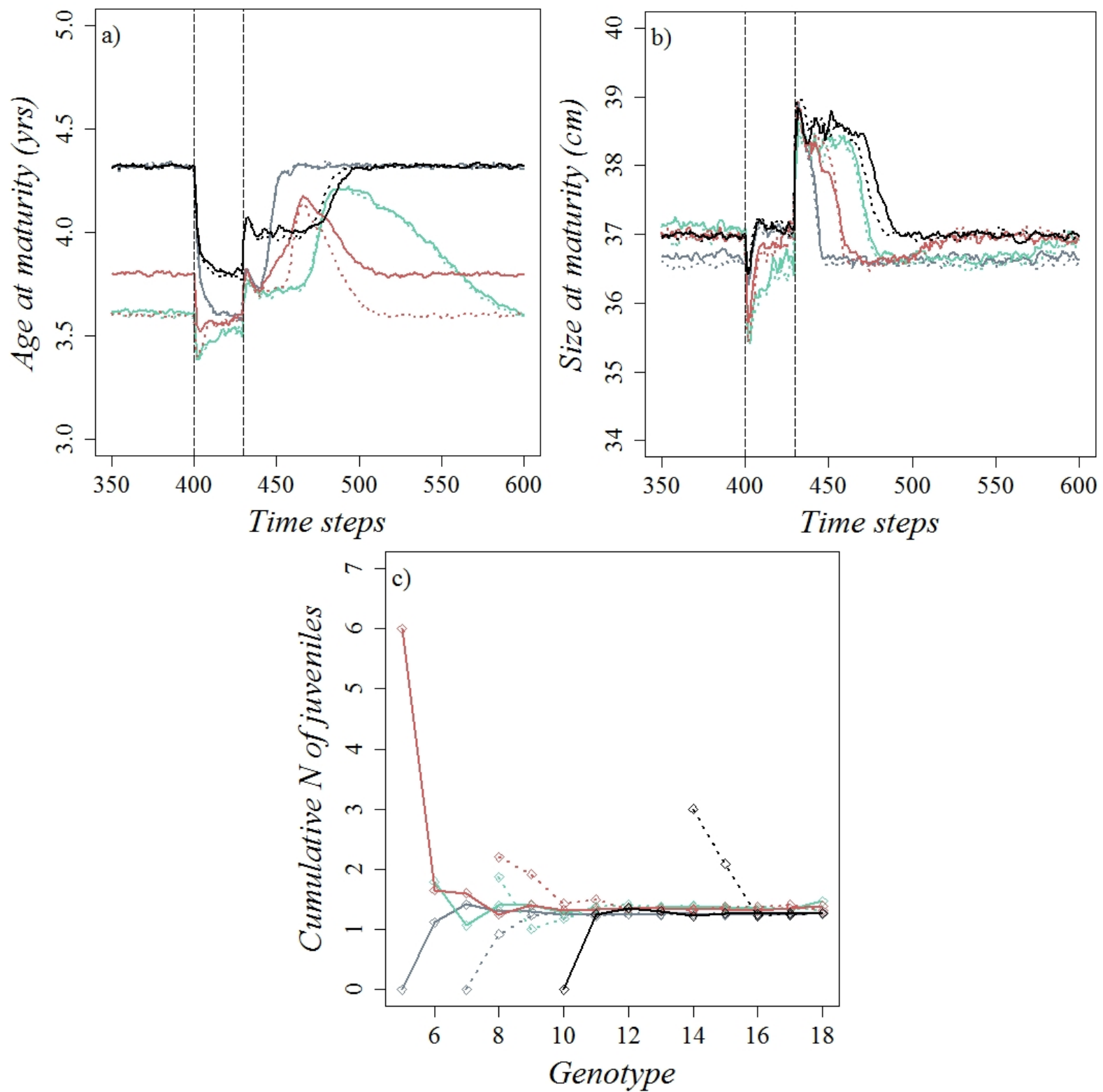

1113 Figure 5. Average values of hake individual parameters showing the age (a) and size at maturity

1114 (b), and genotypic diversity (c) with respect to each scenario. Plots a) and b) are plotted against

1115 simulation time steps where the fishing period is denoted with vertical, dashed lines (400-430). In

1116 plot $\mathrm{c})$, the cumulative number $(\mathrm{N})$ of juveniles is plotted against the genotype values. In all plots,

1117 the dotted lines denote the non-evolutionary scenarios, whereas the bold lines denote the

1118 evolutionary scenarios. All reference scenarios are depicted in black color, while no-predation, FRII

1119 and FRIII scenarios are depicted in grey, green and red colors, respectively. 


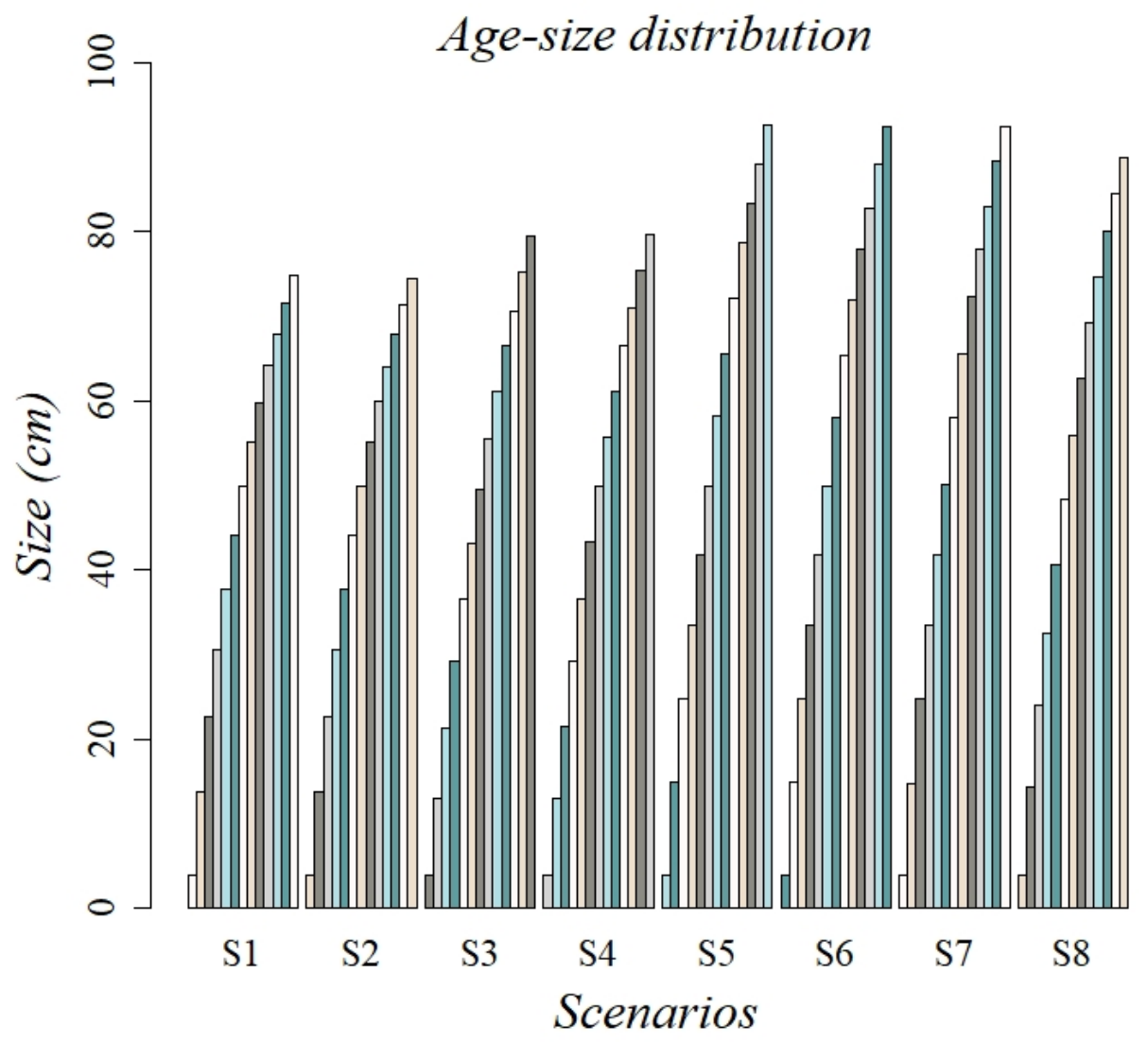

1132

Figure 6. Hake demographic structure based on each scenario. The $\mathrm{x}$-axis denotes the scenarios as:

S1) non-evolutionary scenario without predation and a sex-specific difference in $L_{\infty}$ (reference

1135 scenario without evolution); S2) evolutionary scenario without predation and a sex-specific difference in $L_{\infty}$ (reference scenario with evolution); S3) non-evolutionary scenario without predation; S4) evolutionary scenario without predation; S5) non-evolutionary scenario with FRII predation; S6) evolutionary scenario with FRII predation; S7) non-evolutionary scenario with FRIII predation, and S8) evolutionary scenario with FRIII predation. Each bar per scenario depicts the average size at age as well as each age category ranging from $0-12$ years. Size at $L_{0}$ (first size bar) 1141 is the same for all scenarios and set to $3.9 \mathrm{~cm}$. 

1170 Figure 8. Hake and bottlenose dolphin

1171 population dynamics under fishing

1172 pressure with respect to each scenario.

1173 Average values of the following

1174 population parameters are presented: a)

1175 caught hake biomass; b) hake and

1176 bottlenose dolphin density ratio; and c)

1177 bottlenose dolphin density. Simulation

1178 time steps (x-axis) are divided by

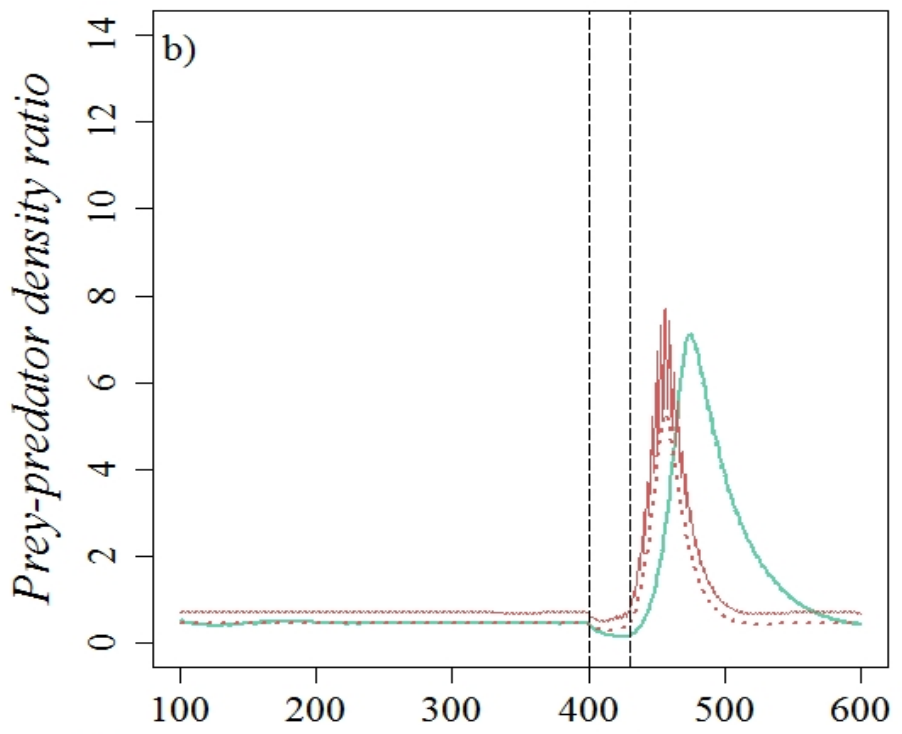

vertical dashed lines into pre-fishing $(0$ 399), fishing (400-430), and recovery

periods (431-600), although plot a)

only shows the fishing period. Dotted

and bold lines depict non-evolutionary

and evolutionary scenarios,

respectively, where a grey color denotes scenarios without predation, green FRII,

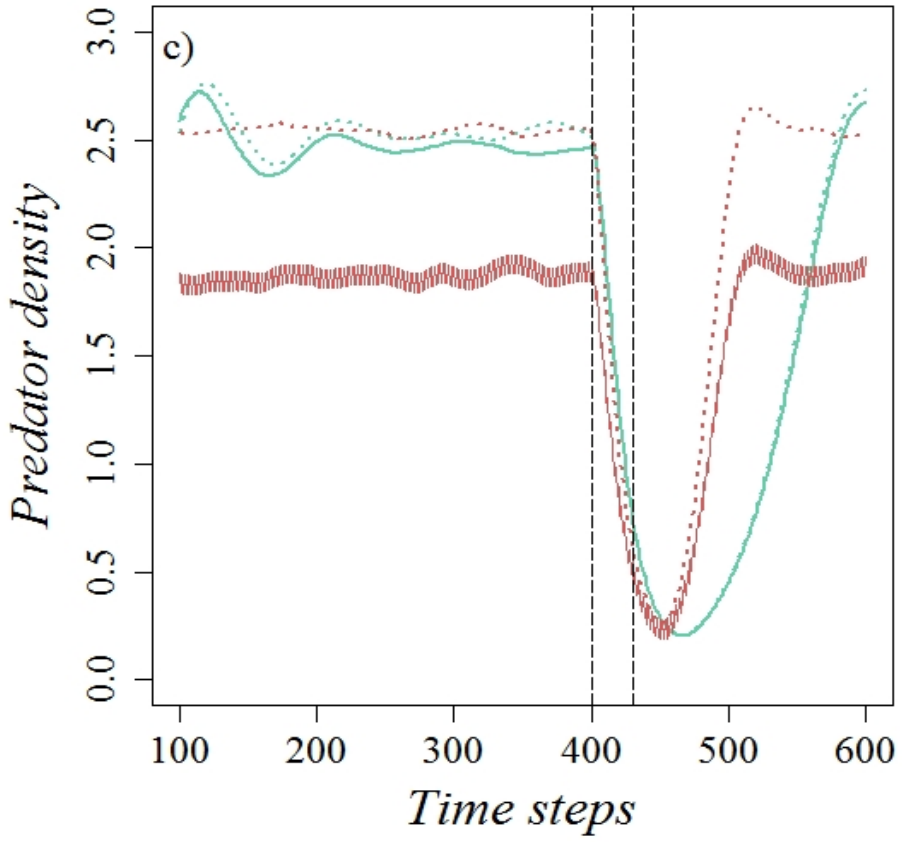

and red FRIII predation scenarios.

Reference scenarios are denoted in black only in plot a). 